\title{
Cultural values, emotional intelligence, and conflict handling styles: A global study
}

Citation for published version (APA):

Gunkel, M., Schlägel, C., \& Taras, V. (2016). Cultural values, emotional intelligence, and conflict handling styles: A global study. Journal of World Business, 51(4), 568-585.

https://doi.org/10.1016/j.jwb.2016.02.001

Document status and date:

Published: 01/06/2016

DOI:

10.1016/j.jwb.2016.02.001

Document Version:

Publisher's PDF, also known as Version of record

Document license:

CC BY-NC-ND

\section{Please check the document version of this publication:}

- A submitted manuscript is the version of the article upon submission and before peer-review. There can be important differences between the submitted version and the official published version of record.

People interested in the research are advised to contact the author for the final version of the publication, or visit the DOI to the publisher's website.

- The final author version and the galley proof are versions of the publication after peer review.

- The final published version features the final layout of the paper including the volume, issue and page numbers.

Link to publication

\footnotetext{
General rights rights.

- You may freely distribute the URL identifying the publication in the public portal. please follow below link for the End User Agreement:

www.umlib.nl/taverne-license

Take down policy

If you believe that this document breaches copyright please contact us at:

repository@maastrichtuniversity.nl

providing details and we will investigate your claim.
}

Copyright and moral rights for the publications made accessible in the public portal are retained by the authors and/or other copyright owners and it is a condition of accessing publications that users recognise and abide by the legal requirements associated with these

- Users may download and print one copy of any publication from the public portal for the purpose of private study or research.

- You may not further distribute the material or use it for any profit-making activity or commercial gain

If the publication is distributed under the terms of Article $25 \mathrm{fa}$ of the Dutch Copyright Act, indicated by the "Taverne" license above, 


\title{
Cultural values, emotional intelligence, and conflict handling styles: A global study
}

\author{
Marjaana Gunkel $^{\mathrm{a}, *}$, Christopher Schlaegel ${ }^{\mathrm{b}}$, Vas Taras ${ }^{\mathrm{c}}$ \\ ${ }^{a}$ Free University of Bozen/Bolzano, Universitätsplatz 1, I-39100 Bolzano, Italy \\ b Otto-von-Guericke University Magdeburg, Universitätsplatz 2, D-39106 Magdeburg, Germany \\ ${ }^{\mathrm{c}}$ University of North Carolina at Greensboro, 349 Bryan Building, P.O. Box 26170, Greensboro, NC 27402-6165, USA
}

\section{A R T I C L E I N F O}

\section{Article history:}

Received 14 January 2015

Received in revised form 3 February 2016

Accepted 9 February 2016

Available online 28 February 2016

\section{Keywords:}

Conflict handling styles

Culture

Cultural value dimensions

Emotional intelligence

\begin{abstract}
A B S T R A C T
While previous research has identified cultural values and emotional intelligence as central determinants of conflict handling styles, little is known about the mechanism through which cultural values impact individuals' preferences for specific conflict handling styles. Based on a multinational dataset including 1527 individuals from ten different cultural clusters, the current study aims to integrate these two literature streams by examining the influence of cultural values on conflict handling styles through emotional intelligence. The results of structural equation modeling and mediation analysis show that in particular uncertainty avoidance and long-term orientation influence preferences for the conflict handling styles of compromising, obliging, and integrating through emotional intelligence. Furthermore, we find that collectivism has a direct negative effect on the preference for a dominating style and that power distance has a direct positive effect on the preference for an avoiding and a dominating style. Our study contributes to a more comprehensive and more integrative understanding of earlier research on the role of culture and emotional intelligence in conflict handling. ๑ 2016 The Authors. Published by Elsevier Inc. This is an open access article under the CC BY-NC-ND license (http://creativecommons.org/licenses/by-nc-nd/4.0/).
\end{abstract}

\section{Introduction}

Whenever individuals interact, such as employees within a project team or managers during a negotiation, interpersonal conflicts are possible. If not resolved, these conflicts may negatively impact the respective outcome of interactions (Thomas, 1992). Conflict handling styles, ${ }^{1}$ which constitute the elements of a

\footnotetext{
* Corresponding author.

E-mail addresses: marjaana.gunkel@unibz.it (M. Gunkel), christopher.schlaegel@ww.uni-magdeburg.de (C. Schlaegel),v_taras@uncg.edu (V. Taras).

${ }^{1}$ In the existing academic literature different terminology has been used to describe the concept of the various modes individuals prefer to handle interpersonal conflicts, such as conflict resolution styles (e.g., Rahim, 1983), conflict resolution strategies (e.g., Boros, Meslec, Curseu, \& Emons, 2010), conflict management behavior (e.g., Doucet et al., 2009), conflict management strategy (e.g. Kaushal \& Kwantes, 2006), conflict management styles (e.g., Antonioni, 1998), and conflict styles among others. In the remainder of this article we use the term 'conflict handling styles'. To our understanding, this term best expresses that the way individuals prefer to behave in conflict situations (i.e., the respective conflict style) is, to a large extent, predetermined by different factors rather than planned. It is not necessarily a specific strategy. Furthermore, a conflict style preferred by an individual influences the way an individual handles a conflict, i.e., conflict styles do not necessarily help to manage (e.g., mediation) or solve a given conflict.
}

classification of different modes for handling interpersonal conflicts (Rahim, 1983), have been identified as a source of reaching more favorable outcomes in a broad spectrum of different conflict situations (e.g., Blake \& Mouton, 1964; Rahim, 1983). Previous research shows that conflict handling styles influence the outcomes at the level of the individual, such as job performance (e.g., Chen, Tjosvold, \& Fang, 2005) and leader effectiveness (e.g., Barbuto, Phipps, \& Xu, 2010). Moreover, previous studies have shown that conflict handling styles also influence outcomes at the firm level, such as joint venture success (Lin \& Germain, 1998), the effectiveness of retail networks (Bradford, Stringfellow, \& Weitz, 2004), as well as innovation and new product performance (Song, Dyer, \& Thieme, 2006; Xie, Song, \& Stringfellow, 1998). As interpersonal conflicts and the way individuals handle conflicts may positively or negatively impact various economic outcomes, it is of growing importance for theory and practice to understand which factors influence individual preferences for different conflict handling styles.

Individuals, to some extent, seem to select conflict handling styles which fit the respective conflict situation (e.g., Rahim, 1986). However, a large number of studies argue and empirically show that the preferences for conflict handling styles are relatively stable across different situations and that an individual's preferred 
conflict handling style is largely predetermined by individual characteristics, such as personality traits (Antonioni, 1998; Park \& Antonioni, 2007; Wood \& Bell, 2008) and demographic characteristics (Gbadamosi, Baghestan, \& Al-Mabrouk, 2014). As conflicts are often highly emotional events, one stream of research has focused on the influence of emotional intelligence on individuals' preferences for conflict handling styles (e.g., Jordan \& Troth, 2004; Shih \& Susanto, 2010; Yu, Sardessai, Lu, \& Zhao, 2006). Emotional intelligence refers to individuals' ability to recognize, use, and regulate emotions (Wong \& Law, 2002). While previous studies show that individuals' emotional intelligence impacts their preferences for specific conflict handling styles, the results are ambiguous (Schlaerth, Ensari, \& Christian, 2013). One potential explanation for the mixed findings might be that previous studies have often failed to consider the culture-specific pattern of emotional intelligence (Gunkel, Schlägel, \& Engle, 2014; Miller, 1997; Shao, Doucet, \& Caruso, 2014).

While previous studies have shown that preferences for conflict handling styles vary substantially across countries (e.g., Doucet, Jehn, Weldon, Chen, \& Wang, 2009; Gabrielidis, Stephan, Ybarra, Pearson, \& Villareal, 1997; Kim, Wang, Kondo, \& Kim, 2007; Posthuma, White, Dworkin, Yánez, \& Swift, 2006; Ting-Toomey et al., 1991), only a small number of studies (e.g., Kaushal \& Kwantes, 2006; Komarraju, Dollinger, \& Lovell, 2008; Morris et al. 1998) has analyzed the underlying reasons for these differences. Prior research suggests that differences in individuals' orientation toward different cultural value dimensions (i.e., the set of aspects that characterize a society according to its apparent place within the continuum of patterns described by the respective aspect) may be one promising explanation for cross-country differences in individual preferences for conflict handling styles (e.g., Holt \& DeVore, 2005; Komarraju et al., 2008).

This study aims to address two shortcomings of the literature that uses cultural value dimensions and emotional intelligence to explain individuals' preferences for conflict handling styles (for a more detailed explanation and an overview of prior studies see Appendix A). First, prior studies, which have examined the relationship between cultural value dimensions and conflict handling styles tested the influence of a single cultural dimension in isolation, especially the individualism/collectivism dimension, neglecting the joint importance of different cultural value dimensions (Littrell, 2012). Thus, little is known about the relative importance of different cultural value dimensions in affecting preferences for different conflict handling styles. In addition, the majority of previous studies have not directly measured cultural value dimensions. Instead they have often used cultural dimension scores by Hofstede (2001) or the GLOBE study (House, Hanges, Javidan, Dorfman, \& Gupta, 2004) to assign cultural values to individuals. For studies performed at the individual level, this approach is problematic as it sets the national culture of a country and the individual cultural orientation of a citizen equal to each other, without directly measuring individual cultural orientations (Brewer \& Venaik, 2014).

Second, we know little about how cultural value dimensions actually influence individuals' preferences and in this way affect the general tendency for individual behavior in different conflict situations. This is problematic as cultural value dimensions are only weak direct predictors of individuals' attitudes and preferences (Taras, Kirkman, and Steel, 2010). Such main effect models provide only descriptive information and do not facilitate theoretical or empirical insights into the more complex relationships, explaining how cultural value dimensions influence individuals' preferences for specific conflict handling styles. Therefore, a better understanding of the underlying mechanism is important for both theory and practice (e.g., Leung, Bhagat, Buchan, Erez, \& Gibson, 2005). Based on a cultural-psychology approach (Miller, 1997), the present study aims to integrate the perspectives of emotional intelligence and cultural value dimensions as separate determinants of conflict handling styles, and proposes a conceptual model that illustrates how cultural value dimensions influence conflict handling styles through emotional intelligence. We validate our conceptual model using survey data from 1527 students from ten different cultural clusters and measure all five of Hofstede's (2001) cultural dimensions at the individual level.

By addressing the identified gaps in the literature our study offers two contributions: First, based on theoretical and empirical knowledge we conceptualize a full set of cultural value dimensions relevant to the formation of preferences for conflict handling styles. Through the concrete theoretical development and empirical testing of these cultural value dimensions, we respond to calls for examining the specific cultural values that influence individuals' preferences for conflict handling styles (Merkin, Taras, \& Steel, 2014; Morris et al., 1998). Second, through the examination of the specific mechanism that underlies the formation of individuals' preferences for specific conflict handling styles and the combination of the two so far independent research streams we provide a more complete and more comprehensive view on how specific cultural dimensions affect the conflict handling preferences of individuals through emotional intelligence-a research area which has been identified as being understudied in this particular field (Nair, 2008; Schlaerth et al., 2013).

\section{Theoretical background}

There is a large body of literature on conflict, as conflict has been identified to be a major aspect of organizational behavior and management (Rahim 1983, Wall \& Callister, 1995). Wall and Callister $(1995,517)$ define conflict as "a process in which one party perceives that its interests are being opposed or negatively affected by another party". Conflicts may take place at various levels (Deutsch, 1990). They can have various causes, such as personal factors, interpersonal factors, and various issues leading to conflict situations. In most cases conflicts upset the involved parties. The disturbance may result in negative emotions (Wall \& Callister, 1995) which then in turn can lead to low job satisfaction (e.g., Derr, 1977) and reduced motivation and performance (Bergmann \& Volkema, 1989). Therefore, the handling of conflict is an important issue for the management of an organization. Blake and Mouton (1964), Thomas (1976), and Rahim (1983) suggest two dimensions for handling interpersonal conflicts: Concern for self and concern for others. A combination of these dimensions results in five styles of handling an interpersonal conflict, namely, integrating style, avoiding style, dominating style, obliging style, and compromising style as presented in Fig. 1 (Rahim, 1983).

Integrating style involves problem solving and requires exchange and examination of the differences to find a solution, which both parties can accept. The obliging style is based on focusing on the commonalities of the parties and reducing the differences. The integration and the obliging styles are referred to as positive-sum styles (win-win) of conflict management. The dominating style of conflict handling is related to a forcing behavior to win one's position. In order to win an objective, often the needs and expectations of the other party are ignored. The avoiding style is related to withdrawal. Such strategy leads to failing to satisfy the concerns of both parties. Dominating and avoiding styles of conflict handling are considered as zero-sum styles (win-lose or lose-lose). Compromising style of conflict handling can be considered as a mixed (no-win/no-lose) style of conflict handling, resulting from the fact that both parties give up something to find a mutually acceptable solution.

Previous studies have identified emotional intelligence and cultural value dimensions as determinants of individuals' 


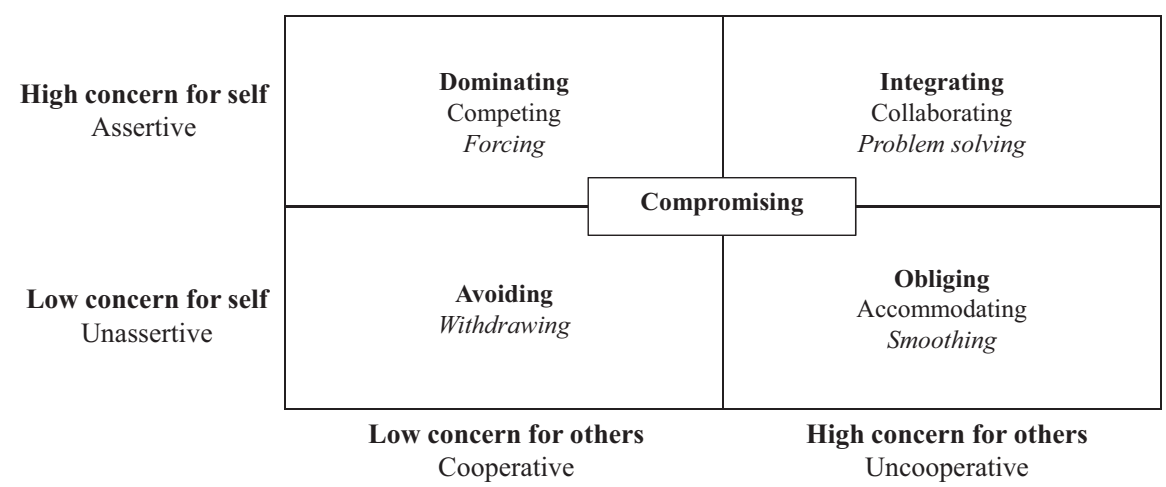

Fig. 1. Two-dimensional taxonomy of conflict handling styles.

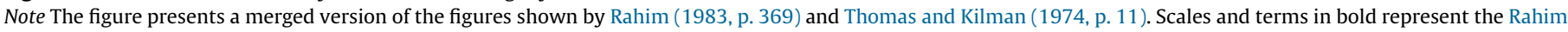

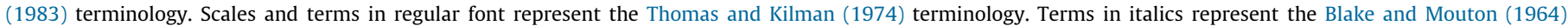
terminology. The term 'Avoiding' is used by both Rahim (1983) as well as Thomas and Kilman (1974). The term 'Compromising' is used by all three References

preference for conflict handling styles. Interpersonal conflicts are often perceived as personal attacks and, as a result, are often emotionally charged (Jehn, 1997). Therefore, an individual's perception of the own ability to recognize one's own and others' emotions as well as to regulate one's own emotions becomes of central importance in an individual's preference for specific conflict handling styles. The cultural-psychology approach (Miller, 1997) argues that psychological processes, in part, are culturally constituted and that cultural values are important in the development of individual capacities, such as emotional intelligence. Previous empirical studies document a culturally based variation in individuals' emotional intelligence (Gunkel et al., 2014; Shao et al., 2014). Consistent with and in an effort to expand this existing knowledge, we develop a conceptual model for the impact of a comprehensive set of cultural value dimensions on the above described set of conflict handling styles mediated by emotional intelligence. Even though our study involves examining culture, we have chosen to examine emotional intelligence instead of another related construct, namely cultural intelligence (e.g., Earley \& Ang, 2003) as we do not aim to explain individual preferences for conflict handling styles in the cross-cultural context in which cultural intelligence would have been a necessary complement next to emotional intelligence. The present study rather focuses on the general (inter-person) preference for a specific handling style. Emotional intelligence may be influenced by the cultural background of individuals making the examination of emotional intelligence instead of cultural intelligence interesting.

\subsection{National culture and conflict handling styles}

Building upon the assumption that individual preferences in general (e.g., Bowles, 1998) and individual preferences of handling conflicts in particular (e.g., Elsayed-EkJiouly \& Buda, 1996; Kirkbride, Tang, \& Westwood, 1991; Ting-Toomey et al., 1991; Wang, Lin, Chan, \& Shi, 2005) are culture specific, we develop hypotheses that link cultural value dimensions to the general tendency that an individual prefers some conflict handling styles over others. In the literature several concepts of culture are present to understand and measure the effect of culture on various outcomes (e.g., Hofstede, 1980; Hofstede, Hofstede, \& Minkov, 2010; House et al., 2004; Inglehart, 1997; Schwartz, 1994, 2006; Triandis, 1995; Triandis \& Gelfand, 1998). While Hofstede (1980, 2001)Hofstede's $(1980,2001)$ concept has been criticized for its sample bias, problems with measurement, and for neglecting individual differences within cultures (e.g., Fang, 2003; Kirkman, Lowe, \& Gibson, 2006; McSweeney, 2013), it is the concept of culture that is most frequently used in the literature in general (Kirkman et al., 2006) and that is also used most widely in the specific context of conflict handling styles (for an overview see Appendix A). To embed our assessment into the body of existing studies and to make our analysis comparable to prior research in this research area, we use Hofstede's (2001) concept of cultural dimensions as our basic framework for analysis. In this study, we also address some of the criticism of Hofstede's concept by collecting original primary data at the individual level and in this way do not rely on Hofstede's (2001) scores and allow for within country variation of cultural value dimensions (c.f., the more detailed explanation in Appendix A).

Culture, the "collective programming of the mind which distinguishes one group from another" (Hofstede, 1980, 25) sets the basic values and norms for a society. Hofstede's (2001) concept of culture consists of five cultural dimensions (Individualism vs. collectivism, masculinity vs. femininity, power distance, uncertainty avoidance, and short-term vs. long-term orientation) that can be used to distinguish different cultures (c.f., Taras et al., 2010). Our general argument is that individuals prefer those conflict styles that fit their cultural values. The concept of culture fit has been used in the literature to explain why management practices are more efficient with respect to employees' work related outcomes if these practices fit the cultural values of the employees (e.g., Lachman, Nedd, \& Hinings, 1994; Newman \& Nollen, 1996). If management practices are not consistent with the cultural values of employees, employees feel dissatisfied and uncomfortable and are thus less motivated to perform well (Newman \& Nollen, 1996). Adopting this fit logic we expect individuals to prefer conflict handling styles that allow these individuals to act in a way that is consistent with their cultural values and therewith within the respective cultural norms. If individuals do not act on the shared expectation of their culture and related preferred practices and cultural standards, these individuals may feel uncomfortable. We suggest that individuals in general will prefer conflict handling styles that are consistent with their cultural values. Prior studies that have focused on a related research stream, namely communication styles in intercultural interaction, support this view as these studies show that in intercultural interactions individuals do not adapt the style of the other party and rather tend to represent their own culture and culturally dominant behaviors (e.g., Laurent, 1983; Pekerti \& Thomas, 2003). Individuals in intercultural interaction are motivated to display preferences and behaviors that are consistent with their culture. Moreover, studies in another related research area, namely individuals' preferences for specific learning styles, show that individuals' prefer those learning styles that are consistent with their cultural values (e.g., Holtbrügge \& 
Mohr, 2010). In the following, we link Hofstede's (2001) five cultural value dimensions to individuals' preferences for specific conflict handling styles.

\subsubsection{Collectivism and preferences for conflict handling styles}

The individualism/collectivism dimension is the cultural value dimension that has been examined most often in the context of conflict handling styles (see Appendix A for an overview). A metaanalysis by Holt and DeVore (2005) shows strong evidence for differences in conflict handling styles across cultures, especially when it comes to the cultural dimensions of individualism vs. collectivism. Individuals from collectivistic cultures select compromising, avoiding (withdrawing), and integrating (problem-solving) styles of conflict handling more often than individuals from individualistic cultures. Dominating (forcing) is more often used in individualistic cultures than collectivistic cultures. Yet, Ting-Toomey et al. (1991) show that obliging is more often used in collectivistic cultures than in individualistic cultures.

Collectivism is related to the focus on collectives and the responsibility related to belonging to a group, whereas individualism is related to the focus on the individual and the ties between individuals are rather loose (Hofstede, 2001). In collectivistic societies values related to the well-being of the group are seen as more important than individualistic values such as achievements of an individual. Our general argument is that people with collectivistic values prefer conflict styles that potentially increase the outcome for all conflict parties involved (i.e., an integrating, avoiding, obliging, and compromising style) as these styles allow these individuals to act in a way that is consistent with their cultural values (e.g., Newman \& Nollen, 1996). People with collectivistic values are less likely to prefer a more confronting conflict handling style (i.e., dominating style) that may increase the outcome of only one conflict party at the costs of the other party as such a behavior would not fit the cultural values of more collectivistic individuals. Therefore, based on the theoretical arguments outlined above, we propose:

Hypothesis 1. Collectivism is positively related to (I) an integrating, (II) an avoiding, (III) an obliging as well as (IV) a compromising conflict handling style and is negatively related to $(\mathrm{V})$ a dominating conflict handling style.

\subsubsection{Uncertainty avoidance and preferences for conflict handling styles}

Only few studies have empirically tested the relationship between uncertainty avoidance and individuals' preferences for different conflict styles. Purohit and Simmers (2006) showed that uncertainty avoidance is positively related to a dominating conflict handling style and that it is also positively related to an avoiding conflict handling style. In line with their theoretical prediction, He, Zhu, and Peng (2002) found that uncertainty avoidance is negatively related to an integrating style and positively related to an obliging style. Contrary to their hypothesized expectation, He and associates found a positive relationship between uncertainty avoidance and an avoiding conflict handling style. In contrast to what they expected, Oudenhoven, Mechelse, and Dreu (1998) found that people from more uncertainty avoiding societies less often prefer problem solving (integrating style) than people from less uncertainty avoiding societies. The mixed findings of these prior studies might result from the use of a small number of countries (two to five countries) and relying on secondary data to categorize whether a country has a higher or lower level of a cultural value dimension (see Appendix A).

High uncertainty avoidance societies prefer structured, organized, and regulated situations, whereas individuals in societies that are characterized by low uncertainty avoidance are more willing to accept the uncertainty and do not require regulations, strict rules, and guidelines (Hofstede, 2001). Applied to the context of preferences for different conflict handling styles, we would thus argue that individuals that tend to circumvent uncertain situations prefer conflict styles that reduce the degree of uncertainty or that at least do not run counter to this cultural value and increase the degree of uncertainty perceived by an individual. Individuals with a tendency to avoid uncertainty are more likely to prefer to solve a conflict using an integrating and a compromising style, as the search for a win-win solution that gives both conflict parties a part of what they want makes the outcome of a conflict more predictable and in this way reduces the uncertainty. This argument is in contrast to the one by He et al. (2002) who rather focus on the differences of conflict parties and the perceived risks related to these differences.

The potential outcomes of a conflict solution can vary which makes it rather difficult to predict the outcome in a given conflict situation. Thus, those scoring high on uncertainty avoidance are also likely to wish to avoid conflict situations all together. People with a higher degree of uncertainty avoidance are also more likely to prefer an obliging style as the high concerns for the needs of the other party and the disposition to accept the position and demands of the other party makes the potential conflict outcome more certain as the individual can better assess which concessions are necessary to reach a solution. People who prefer a dominating style use confrontational and aggressive actions and ignore the needs and expectations of the other conflict party (Rahim, 1983), which puts pressure on the other party and thus might be perceived as being inappropriate. A dominating style might be effective in finding a solution if the conflict reason is less important to the other party or the dominant side is more powerful, which is often not obvious and often remains invisible to conflict parties in the early stage of a conflict. We would thus expect that people with a high degree of uncertainty avoidance do not prefer a dominating style as the response of the other conflict party and therewith the outcome of the conflict is difficult to predict which creates a higher degree of uncertainty. Based on the theoretical arguments, we posit:

Hypothesis 2. Uncertainty avoidance is positively related to (I) an integrating, (II) an avoiding, (III) an obliging as well as (IV) a compromising conflict handling style and is negatively related to $(\mathrm{V})$ dominating conflict handling style.

\subsubsection{Long-term orientation and preferences for conflict handling styles}

Long-term commitment and respect for traditions are important in long-term oriented societies and today's hard work is expected to result in long-term rewards (Hofstede, 2001). With regard to specific preferences for conflict handling styles we argue that longterm orientation will be positively related to those conflict styles that may provide a positive outcome for the parties involved in the conflict (i.e., an integrating, an obliging, and a compromising style) as individuals in more long-term oriented countries value past experience and critically reflect on these experiences (Hofstede, 2001). An outcome that is perceived as being relatively positive would positively influence the experience of the conflict parties and therewith would also positively influence the relationship between the conflict parties, potentially resulting in positive long-term effects. In contrast, if conflicts are not resolved properly (e.g., by avoiding a conflict), they might lead to long-term negative effects (Friedman, Chi, \& Liu, 2006). If the conflict is dominated by a conflict party this might create a rather negative experience for the other conflict party and induce potential negative long-term effects for the relationship. Therefore, individuals that are more long-term oriented will prefer not to dominate a conflict as such preference is more consistent with their cultural values. While several studies examined long-term orientation and conflict styles in the same study (e.g., Ndubisi, 2011; Song et al., 2006; Xie et al., 1998), to the best of our knowledge no study directly assessed and reported 
results (e.g., correlation coefficients or statistical comparison of country mean values) for the association between long-term orientation and conflict handling style. Based on the theoretical arguments we posit:

Hypothesis 3. Long-term orientation is positively related to (I) an integrating, (II) an obliging, as well as (III) a compromising conflict handling style and is negatively related to (IV) an avoiding and (V) a dominating conflict handling style.

\subsubsection{Power distance and preferences for conflict handling styles}

Cultures that are characterized by high power distance accept and expect inequalities of power and wealth distribution within the society (Hofstede, 2001). Equality and opportunity for everyone is considered important in low power distance cultures, while hierarchical differences in social relationships are expected in high power distance cultures. Related to the conflict context, we expect that individuals with a higher degree of power distance are more likely to prefer those conflict handling styles that allow them to maintain power distance in social interactions and are less likely to prefer those conflict handling styles that reduce power distance as these styles might lead to undesirable outcomes. With regard to an integrating style, an obliging style, and a compromising style we suggest that these three conflict handling styles are less suitable to maintain power distance and to act consistent with this cultural value. This prediction is based on the fact that for all three styles the individual cooperates and gives in a little to get a little (or nothing). To reach a conflict solution and therewith to achieve an outcome that falls between the two conflict party positions these three styles rely on cooperative actions which is not consistent with a high power distance orientation. With regard to an avoiding conflict handling style we argue that individuals with a high power distance are more likely to prefer this conflict style compared to individuals with a low power distance orientation. In avoiding a conflict potential inequalities can persist while a conflict solution might change the current status of the conflict parties and might challenge the existing authority and power and thus result in a redistribution of power and control. The dominating style is characterized by exertion of control, low tolerance for alternative views, a competitive orientation, and a rather uncooperative behavior to meet own needs in a conflict (Rahim, 1983). We expect that individuals with a high power distance orientation will prefer a dominating style as they expect more inequality and feel uncomfortable to act within a collaborative context. In sum, we expect that power distance increase individuals' preferences for an avoiding style as well as a dominating style and decreases the preferences for an integrating, an obliging, as well as a compromising conflict handling style.

Relatively few studies have tested the association between power distance and the different conflict handling styles. Purohit and Simmers (2006) showed that power distance is positively related to a dominating style of conflict handling and that power distance is also positively related to the conflict handling strategy of avoiding. He et al. (2002) found that power distance is positively associated with an avoiding and an obliging conflict handling style and negatively related to an integrating conflict handling style. Oudenhoven et al. (1998) found a positive relationship between power distance and an integrating style. The findings of these existing studies are mixed and sometimes contradictory which might be again explained by the small number of studies included in these studies and the use of secondary data to characterize countries with respect to different cultural dimensions. Based on the theoretical arguments outlined above we posit:

Hypothesis 4. Power distance is positively related to (I) an avoiding as well as (II) a dominating conflict handling style and is negatively related to (III) an integrating, (IV) an obliging, as well as (V) a compromising conflict handling style.

\subsubsection{Masculinity and preferences for conflict handling styles}

Few studies have examined the influence of masculinity/ femininity on individual preferences for specific conflict handling styles. Gabrielidis et al. (1997) found a relationship between femininity and obliging, whereas integrating (collaborating) was related to both masculinity and femininity. He et al. (2002) found a negative relationship between masculinity and a dominating style but no significant effect for the other four conflict styles. Oudenhoven et al. (1998) found that individuals from more feminine countries tend to prefer an integrating style. The mixed findings of previous studies may again be a result of the rather small number of countries (two to five countries) that have been included in these studies and the indirect assessment of cultural values via secondary data. Masculine work roles of achievement, control, and power are reinforced in masculine cultures whereas more emphasis is placed on softer factors in feminine cultures, such as cooperation and modesty (Hofstede, 2001). In more masculine cultures people tend to be more assertive, competitive, and strong (Hofstede, 2001). Within the context of conflict handling styles we would expect a preference for those conflict handling styles that better reflect the characteristics of this cultural value dimension. More masculine cultures are less likely to prefer a rather unassertive conflict style (i.e., an obliging style). People with a more masculine cultural orientation are also less likely to prefer rather cooperative styles, such as the compromising and the integrating conflict handling style. Individuals from more masculine cultures are less likely to prefer an avoiding style and will rather try to find a solution for a conflict and will strive to have their own needs met even if this would mean to be uncooperative (i.e., a dominating style). Overall, masculinity is expected to be positively associated with a dominating style and to be negatively associated with an integrating, an avoiding, an obliging, as well as a compromising style. Based on the theoretical arguments we hypothesize:

Hypothesis 5. Masculinity is negatively related to the conflict handling styles of (I) integrating, (II) avoiding, (III) obliging, and (IV) compromising and is positively related to a (V) dominating conflict handling style.

\subsection{Emotional intelligence and conflict handling styles}

Emotional intelligence plays an important role in conflict handling as constructive solutions for conflict may require compromises that are based on the ability to recognize and regulate emotions (Schlaerth et al., 2013). Emotional intelligence is "the ability to monitor one's own and others' feelings and emotions, to discriminate among them and to use this information to guide one's thinking and actions" (Salovey \& Mayer, 1990, 189). It is composed of four dimensions: (1) Appraisal and expression of emotion in the self - self emotional appraisal, (2) appraisal and recognition of emotion in others - others' emotional appraisal, (3) regulation of emotion in the self - regulation of emotion, and (4) use of emotion to facilitate performance - use of emotion (Mayer \& Salovey, 1997; Salovey \& Mayer, 1990).

Interpersonal conflict situations at work often arouse negative emotions, such as anger, mistrust, and deviant behavior (Bruk-Lee \& Spector, 2006; Schieman \& Reid, 2008). While emotional intelligence is related to the recognition and controlling of own and others' emotions it may play a significant role in lowering interpersonal conflict, as emotional intelligent employees are able to regulate their emotions and use their ability to reduce conflict and maybe even solve conflict (Mulki, Jaramillo, Goad, \& Pesquera, 2015). Schutte, Malouff, Simunek, McKenley, and Hollander (2002) 
show that emotional intelligent individuals are better able to handle threats to their positive attitude in negative situations, which can also be of significant importance in work related conflict situations. Recent meta-analytic evidence (Schlaerth et al., 2013) also suggests that individuals with high emotional intelligence are able to manage conflict more constructively. Along the same lines, Jordan and Troth (2004) show that individuals with high emotional intelligence are able to solve conflicts more productively than individuals scoring low on emotional intelligence.

As discussed above, national culture influences the conflict handling styles of individuals and emotional intelligence affects conflict handling styles of individuals but emotional intelligence is also influenced by national culture. Previous studies have demonstrated cultural variation in emotional expression (Marsh, Elfenbein, Ambady, 2003) as well as in the accuracy on emotion recognition (Elfenbein \& Ambady, 2003). Emotions are also regulated to a different extend in different cultures (Hofstede, 2001) and some cultures tend to use emotions more than others (Bono \& Barron, 2008). All of these aspects contribute to the examination of culture's influence on emotional intelligence. Gunkel et al. (2014) show in their empirical study that the four dimensions of emotional intelligence (self emotional appraisal, others' emotional appraisal, regulation of emotion, and use of emotion) proposed by Salovey and Mayer (1990) are all influenced by national culture. Especially the cultural value dimensions of collectivism, uncertainty avoidance, and long-term orientation have an influence on the various dimensions of emotional intelligence and this impact is mainly positive across the countries, however, the existing studies have mainly concentrated on single facets of emotional intelligence and not on the concept of emotional intelligence as a whole. Gunkel et al. (2014) contribute to the rather sporadic literature of national culture's influence on emotional intelligence by using the model of Oyserman, Kemmelmeier, and Coon (2002) discussing the influence of culture on psychological functioning. Their model suggests that psychological processes are culturally grounded as culturally diverse beliefs and standards influence which behaviors, and therewith preferences for a specific behavior, are considered to be appropriate in a society. Based on the broad empirical evidence, Taras et al. (2010) suggest in their model that cultural values influence the affect, attitudes, perceptions and cognitive schema of individuals, such as emotional intelligence, serving as mediators on the behavior of individuals and influencing their behavior. In line with these theoretical concepts, we believe that national culture influences the ways in which minds work, and thereby, influence the emotional intelligence of individuals in conflict situations. Relating to the results of Taras et al. (2010) we suggest that emotional intelligence acts as a mediator in the process of culture's influence on conflict handling styles.

Our analysis focuses on the influence of Hofstede's (2001) five cultural dimensions of collectivism, uncertainty avoidance, longterm orientation, power distance, and masculinity. The dimension individualism vs. collectivism can be related to emotional expression: individuals from individualistic cultures display emotions more than those in collectivistic cultures as individualistic cultures encourage a freer expression of emotions (Matsumoto, Yoo, Nakagawa, \& Multinational Study of Cultural Display Rules, 2008). Individualistic cultures encourage the uniqueness of their members, and therefore, open communication of emotions is considered as normal and may even be encouraged (Matsumoto, 1989). At the same time, people in individualistic cultures are not able to recognize negative emotions easily (Matsumoto, 1989). However, being able to recognize one's own and other's emotions could provide a coordination mechanism within collectivist societies (Gunkel et al., 2014). Also the regulation of emotions may play a key role in the success in a collective society. Therefore, collectivism is positively related to emotional intelligence.
Uncertainty avoidance, on the other hand, influences the expressivity of emotions. High uncertainty avoidant cultures are more expressive cultures (Palmer, Gignac, Ekermans, \& Stough, 2008; Sharma, Deller, Biswal, \& Madal, 2009). As uncertainty is considered as a threat in high uncertainty avoidant cultures (Hofstede, 2001), individuals in these cultures may be observing emotions more thoroughly in order to avoid any future uncertainties (Gunkel et al., 2014), suggesting a positive relation between uncertainty avoidance and emotional intelligence. Long-term oriented cultures are focused on building relationships (Hofstede, 2001). Emotions may be suppressed in long-term oriented cultures (Matsumoto, Nezlek, \& Koopmann, 2007) in order to benefit these long-term relationships. That is, emotions may not be shown in order to please or not to hurt the other party with the purpose of not harming or endangering the longterm relationship. In this context, especially negative emotions may be suppressed in order not to hurt long-term relationships. Gunkel et al. (2014) suggest that individuals in long-term oriented cultures invest time and effort to understand others' emotions, their own emotions, and also regulate and use them in order to benefit from the future long-term relationship with the counterpart. That is, longterm orientation entails emotional intelligence.

Emotional intelligence has also been demonstrated to influence the different conflict handling styles (Schlaerth et al., 2013). Jordan and Troth (2004) and Kaushal and Kwantes (2006) suggest that low levels of emotional intelligence are related to the conflict handling styles of avoiding and dominating, as individuals with lower levels of emotional intelligence have less the ability to be aware, control, and manage emotions. Therefore, negative conflict handling styles (avoiding and dominating) are selected. Goleman (1998) suggests that high emotional intelligence is related to superior conflict resolution skills and engagement, such as integrating (collaborative) conflict handling style. Jordan and Troth (2004) further suggest that the conflict handling styles of integrating, obliging, and compromising are related to higher levels of emotional intelligence as individuals with high levels of emotional intelligence are able to recognize, control, and use their and others' emotions. They are likelier to select positive conflict handling strategies. Based on the existing literature discussed above, we propose the following hypotheses:

Hypotheses 6, 7, 8. Emotional intelligence mediates the relationship between collectivism and the five conflict handling styles (Hypothesis 6), between uncertainty avoidance and the five conflict handling styles (Hypothesis 7), as well as between long-term orientation and the five conflict handling styles (Hypothesis 8) in such a way that collectivism, uncertainty avoidance, and long-term orientation are positively related to emotional intelligence and emotional intelligence in turn is (a) positively related to integrating, (b) negatively related to avoiding, (c) negatively related to dominating, (d) positively related to obliging, and (e) positively related to compromising styles of conflict handling.

Fig. 2 depicts our conceptual model.

\section{Methodology}

\subsection{Sample and data collection procedure}

To test the hypothesized relationship, we conducted an online survey that was part of a virtual international collaboration project conducted at 71 universities. While the use of student samples is controversially discussed in the literature (Bello, Leung, Radebaugh, Tung, \& Van Witteloostuijn, 2009), in examining the effect of cultural values on individual preferences, such as conflict handling styles, a student sample can be considered as appropriate as it allows to largely isolate the influence of cultural value 


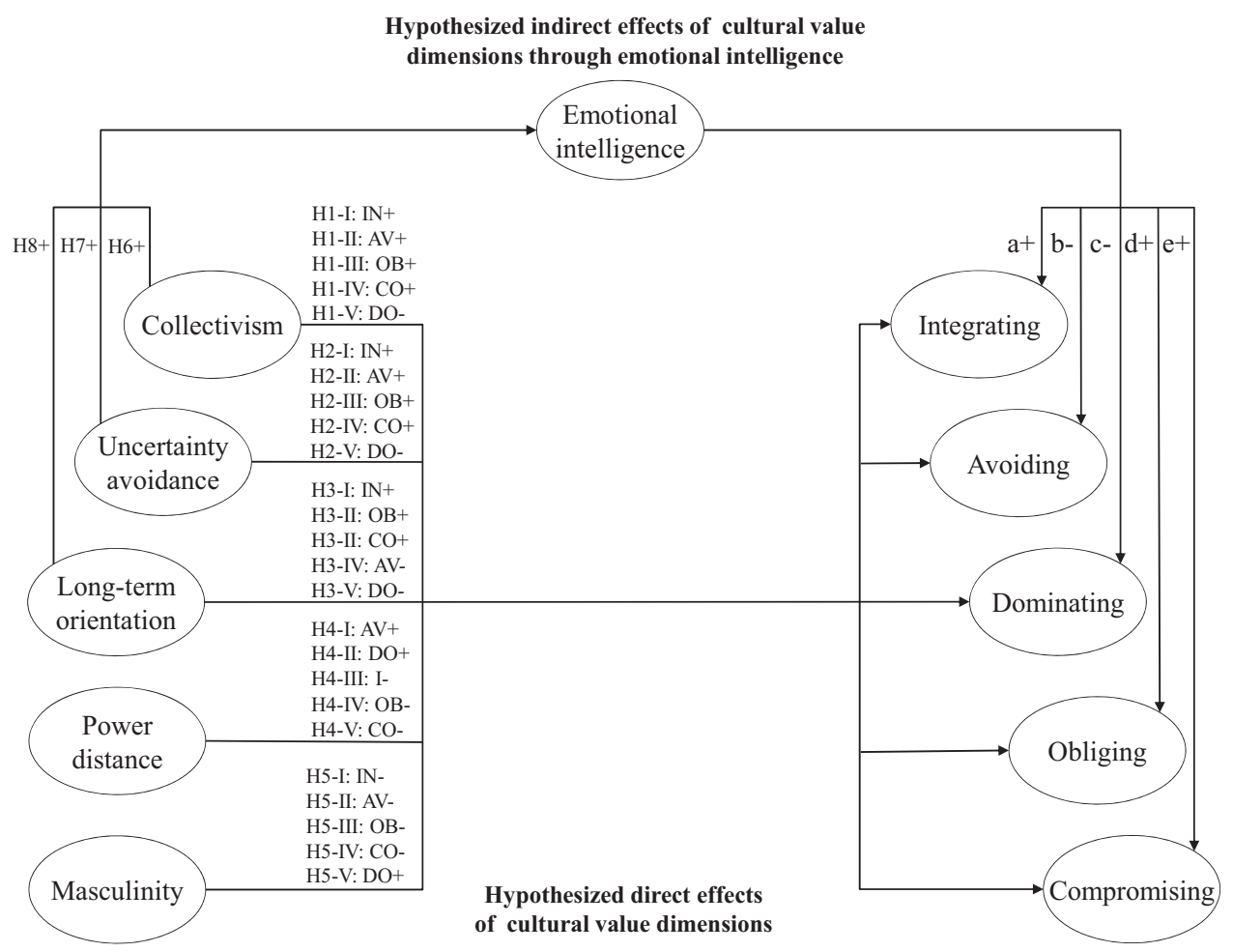

Fig. 2. Conceptual model.

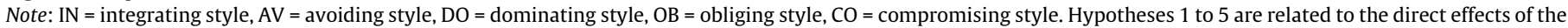

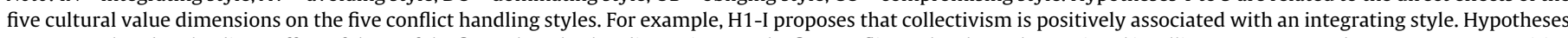

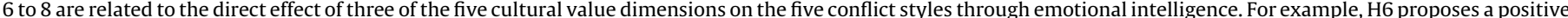

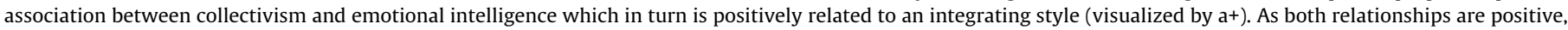
emotional intelligence is

dimensions on emotional intelligence and conflict handling styles. The effects of other potential socio-cultural influences, such as education, status, and income are reduced by using a more homogeneous group of participants with comparable demographic characteristics, such as business students (van De Vijver \& Leung, 1997). Importantly, most of the concerns related to the use of student samples do not apply to the present study. Typically, convenience student samples are composed of young inexperienced people and the studies rely on short-term in-classroom experiments for a small course credit that bear little resemblance of the workplace settings. In contrast, of the present study about half of the sample were Master's students, many with substantial work experience, while the rest were undergraduate students, most with at least some work experience. The students worked in teams of about seven students. The task was to develop a solution to a real-life business challenge presented by real-life companies. Each client company made their CEO or other senior manager available to the students, just as it would be in the real consulting project. The project lasted the entire semester and the active teamwork phase lasted eight to nine weeks during which the team members communicated on the daily basis. Just like in the organizations settings, the stakes were high: the project accounted for $20-50 \%$ of the course grade, the most successful teams were eligible for post-market commission and travel stipends to a project symposium, and many were offered internships and jobs by the client organizations. In every aspect, the project was a real consulting project with real compensation and career growth opportunities; it just happened to be that the participants were enrolled in it via their academic programs.

A total of 1527 graduate and undergraduate business students completed surveys before, during, and at the end of the project. The average age of respondents was 23 years. Half of the respondents
(50.1\%) were females. The participants were citizens of 83 countries. The majority of the respondents $(n=1278)$ were born, raised, and reside in the respective country at the time of the data collection. The sample also includes respondents that studied abroad at the time of the data collection $(n=249)$. The inclusion of countries in the sample focused on representation of the major cultural regions of the world so as to maximize variation in cultural norms and values (Franke \& Richey, 2010). The total sample includes 16 countries with more than or close to 30 participants from each country, covering ten of the eleven cultural clusters identified by Ronen and Shenkar (2013). Descriptive statistics for these country samples and cultural clusters are presented in Table 1. Countries that cover the Near East cultural cluster, including Greece and Turkey, are not included in the sample, which represents a shortcoming of the present study that is further discussed in the limitations section. The data were collected online as part of the team progress report surveys. All data were handled according to the research ethics guidelines. All participants completed the survey concurrently.

\subsection{Measures}

\subsubsection{Cultural dimensions}

We measured Hofstede's (2001) cultural value dimensions, operationalized at the individual level, using the cultural values scale (23 items in total) by Yoo, Donthu, and Lenartowicz (2011). Following the recommendations in the literature (e.g., Kirkman et al., 2006; Littrell, 2012; Tsui, Nifadkar, \& Ou, 2007), we examined the effects of all five dimensions. While national culture is very useful for the study of nations and societies, the operationalization of culture at the individual level is more important when the purpose is to explain individual attitudes and preferences. The 
Table 1

Sample descriptive statistics.

\begin{tabular}{|c|c|c|c|}
\hline $\begin{array}{l}\text { Cultural cluster } \\
\text { country }\end{array}$ & Sample size & $\begin{array}{l}\text { Females } \\
(\%)\end{array}$ & Mean age (SD) \\
\hline \multicolumn{4}{|l|}{ Arab } \\
\hline UAE & 39 & $24(62)$ & $21(1.62)$ \\
\hline \multicolumn{4}{|l|}{ African } \\
\hline Ghana & 52 & $13(25)$ & $30(3.91)$ \\
\hline Nigeria & 51 & 30 (59) & $26(3.34)$ \\
\hline \multicolumn{4}{|l|}{ Anglo } \\
\hline UK & 11 & $5(45)$ & $21(.52)$ \\
\hline USA & 450 & $261(58)$ & $23(5.02)$ \\
\hline \multicolumn{4}{|l|}{ Confucian Asia } \\
\hline China & 52 & $27(52)$ & $21(3.45)$ \\
\hline South Korea & 21 & $9(43)$ & $23(1.61)$ \\
\hline \multicolumn{4}{|l|}{ East Europe } \\
\hline Bulgaria & 5 & $3(60)$ & 24 (3.39) \\
\hline Estonia & 25 & $16(64)$ & $23(3.51)$ \\
\hline Latvia & 10 & $5(50)$ & 27 (3.68) \\
\hline Lithuania & 30 & $15(50)$ & $21(.82)$ \\
\hline Poland & 6 & $6(100)$ & $24(2.40)$ \\
\hline Romania & 10 & $8(80)$ & $25(5.24)$ \\
\hline Ukraine & 40 & $23(58)$ & 21 (1.67) \\
\hline \multicolumn{4}{|l|}{ Far East } \\
\hline India & 107 & $52(49)$ & $24(2.71)$ \\
\hline Indonesia & 30 & $14(47)$ & $20(.92)$ \\
\hline Malaysia & 22 & $17(77)$ & $22(.66)$ \\
\hline Pakistan & 103 & $42(41)$ & $21(1.56)$ \\
\hline \multicolumn{4}{|l|}{ Germanic } \\
\hline Germany & 29 & $14(48)$ & $23(2.12)$ \\
\hline \multicolumn{4}{|l|}{ Latin America } \\
\hline Brazil & 89 & $41(46)$ & $22(2.47)$ \\
\hline Chile & 14 & 4 (29) & 24 (1.69) \\
\hline Columbia & 54 & $39(72)$ & $22(4.08)$ \\
\hline Dominican Republic & 26 & $13(50)$ & $21(.62)$ \\
\hline Ecuador & 48 & $24(50)$ & $32(6.01)$ \\
\hline Mexico & 16 & $6(38)$ & $24(2.66)$ \\
\hline Peru & 13 & $3(23)$ & $22(2.53)$ \\
\hline \multicolumn{4}{|l|}{ Latin Europe } \\
\hline Spain & 28 & $4(50)$ & $24(4.56)$ \\
\hline \multicolumn{4}{|l|}{ Nordic } \\
\hline Netherlands & 32 & $11(34)$ & $23(1.74)$ \\
\hline Norway & 12 & $4(33)$ & $25(1.27)$ \\
\hline
\end{tabular}

Note: Countries with at least 5 participants are presented. Detailed results for all 89 countries are available from the authors upon request.

degree to which an individual shows the same orientation toward cultural values compared to cultural values at the national level might vary due to different cultural backgrounds within a country or due to tradition of immigration in a country (Brewer \& Venaik, 2014; Yoo et al., 2011). Moreover, meta-analytic evidence suggests that not all cultural value dimensions are stable and that cultural values seem to change over time (e.g., Taras, Steel, \& Kirkman, 2012). Therefore, we followed the recommendation in the literature (Taras, Rowney, \& Steel, 2013; Taras et al., 2010) and directly measured the cultural value dimensions at the individual level, accounting for intra-country variations in cultural values and potential changes in cultural values that might have taken place.

Collectivism was assessed with six items (e.g., "Group welfare is more important than individual rewards.", and "Group success is more important than individual success."). The Cronbach alpha was .69, the average variance extracted (AVE) was .51, and the composite reliability (CR) was .75 in the full sample. Uncertainty avoidance $(\alpha=.68 ; \mathrm{AVE}=.49 ; \mathrm{CR}=.74)$ was measured using five items (e.g., "Instructions for operations are important." and "It is important to have instructions spelled out in detail so that I always know what I'm expected to do."). The response scales ranged from 1 , "strongly disagree," to 5, "strongly agree" for all items that measured these two cultural dimensions. Long-term orientation $(\alpha=.64 ; \mathrm{AVE}=.49 ; \mathrm{CR}=.73)$ was measured using six items (e.g., "Personal steadiness and stability" and "Working hard for success in the future") and was measured with a scale that ranged from 1 , "very unimportant," to 5, "very important." Power distance $(\alpha=.74 ; \mathrm{AVE}=.49 ; \mathrm{CR}=.79)$ was assessed using five items (e.g., "People in higher positions should make most decisions without consulting people in lower positions." and "People in lower positions should not disagree with decisions by people in higher positions."). Masculinity ( $\alpha=.72 ; \mathrm{AVE}=.51 ; \mathrm{CR}=.76)$ was measured using four items (e.g., "Solving difficult problems usually requires an active, forcible approach, which is typical of men." and "It is more important for men to have a professional career than it is for women."). The response scales ranged from 1, "strongly disagree," to 5, "strongly agree" for all items that measured these two cultural dimensions.

\subsubsection{Emotional intelligence}

We measured emotional intelligence using Wong and Law's (2002) instrument to assess the four dimensions (18 items). Self emotional appraisal $(\alpha=.82 ; \mathrm{AVE}=.55 ; \mathrm{CR}=.83)$ was assessed using four items (e.g., "I have a good understanding of my own emotions." and "I really understand what I feel."). Others' emotional appraisal $(\alpha=.82 ; \mathrm{AVE}=.56$; $\mathrm{CR}=.84)$ was measured with four items (e.g., "I am a good observer of others' emotions." and "I have a good understanding of the emotions of people around me.”). Use of emotion ( $\alpha=.83$; AVE $=.56$; $C R=.83$ ) was assessed with four items (e.g., "I am a self-motivated person." and "I would always encourage myself to try my best."). Regulation of emotion $(\alpha=.84 ; \mathrm{AVE}=.58 ; \mathrm{CR}=.84)$ was measured with four items (e.g., "I am quite capable of controlling my emotions." and "I have good control of my own emotions."). The items contributing to the emotional intelligence dimensions were measured on a scale anchored at 1, "strongly disagree," and 5 "strongly agree."

\subsubsection{Conflict handling styles}

The five conflict handling styles were measured using the 28 item scale by Rahim (1983). The integrating style $(\alpha=.79$; $\mathrm{AVE}=.56 ; \mathrm{CR}=.79$ ) was measured with seven items (e.g., "I try to investigate an issue with my teammates to find a solution acceptable to us." and "I exchange accurate information with my teammates to solve a problem together."). The avoiding style $(\alpha=.75 ; \mathrm{AVE}=.50 ; \mathrm{CR}=.80)$ was measured with six items (e.g., "I usually avoid open discussion of my differences with my teammates." and "I try to keep my disagreement with my teammates to myself in order to avoid hard feelings."). The dominating style $(\alpha=.77$; AVE $=.54 ; \mathrm{CR}=.78)$ was measured with five items (e.g., "I use my authority to make a decision in my favor." and "I sometimes use my power to win a competitive situation."). The obliging style $(\alpha=.65 ; \mathrm{AVE}=.49 ; \mathrm{CR}=.74)$ was measured with six items (e.g., "I generally try to satisfy the needs of my teammates." and "I give in to the wishes of my teammates."). A compromising style $(\alpha=.67 ; \mathrm{AVE}=.50 ; \mathrm{CR}=.75)$ was assessed with four items (e.g., "I usually propose a middle ground for breaking deadlocks." and "I try to find a middle course to resolve an impasse."). All items were measured on a scale ranging from 1, "strongly disagree" to 5 , "strongly agree."

\subsubsection{Controls}

We controlled for two demographic variables that have been found to be significantly related to emotional intelligence (e.g., Gunkel et al., 2014) as well as conflict handling styles (e.g., Brewer, Mitchell, \& Weber, 2002; Gbadamosi et al., 2014) in previous research. Age was measured in years. Gender was measured as a dichotomous variable ( 1 for female, 0 for male).

While it is recommended to provide participants with surveys in their own national language (e.g., Harzing, 2005, 2006), we developed and used an English language questionnaire as we could not foresee the nationality and respective language of the participants. The language of instruction of the international 
collaboration project was English in all countries. To account for the use of a non-native questionnaire in the majority of the countries, we used five items to test English proficiency and controlled for a potential influence of different English skills on the results. In addition, we tested for measurement invariance across the different cultural clusters (the results are presented below) to ensure that the participants understood the surveys in a consistent manner across the cultural clusters.

\section{Analysis and results}

\subsection{Measurement model, measurement invariance, and common method variance}

We used the maximum likelihood method to examine the measurement model, test for measurement invariance across the cultural clusters, and to estimate the proposed conceptual model. The chi-square statistic is not an adequate test of model fit given large sample sizes $(n>500)$, such as our pooled sample, and small sample sizes $(n<100)$, such as some of the cultural cluster samples in our study (Iacobucci, 2010). Consequently, we used the comparative fit index (CFI), and the root mean square error of approximation (RMSEA) to evaluate the goodness of fit because these two indices are not directly related to sample size. Values greater than .90 are commonly interpreted to represent acceptable fit for the CFI and values less than .08 are an acceptable fit for the RMSEA (Browne \& Cudeck, 1992).

Measurement invariance is a prerequisite for testing theory in cross-cultural research in general (Harzing, Reiche, \& Pudelko, 2013; Nimon \& Reio, 2011; Schmitt \& Kuljanin, 2008) and in the context of conflict handling styles in particular (Weldon \& Jehn, 1995). We followed the recommendations in the literature (Byrne, 2008; Byrne \& van De Vijver, 2010; Hult et al., 2008) and conducted confirmatory factor analysis (CFA) for each cultural cluster independently to assess the reliability and validity of all constructs and to obtain the best fitting measurement model for each cultural cluster, which is necessary to attain an acceptable baseline multigroup model for the multi-group confirmatory factor analysis (MGCFA). Given the small sample sizes for the majority of the countries we used the cultural clusters instead of the individual countries for the CFA and the MGCFA, which is a limitation that is further discussed in the limitation section. In the analyses of the individual cultural cluster, fit improved by dropping items for the five cultural value dimensions and the five conflict handling styles. The revised measurement model provided at least three items for each latent variable. The remaining measured items loaded similarly on the latent variables, confirming the form of the construct. Each cultural cluster CFA met acceptable level of model fit $(\mathrm{CFI}>.90, \mathrm{RMSEA}<.08)$, confirming that the form of the latent variables seems appropriate in different cultural clusters. We used the baseline model to test configural, metric, and scalar invariance for the five cultural value dimensions, the four emotional intelligence facets, and the five conflict handling styles.

The results of the MGCFA are presented in Table 2 . The results for all three variable groups show that configural invariance is achieved, indicating that the same items load on the respective variable in each of the different cultural clusters. While constraining the item loadings to be invariant across the cultural clusters did reduce the model fit to a small degree, the model comparison shows that the change in CFI is less than the recommended threshold of .01 (Cheung \& Rensvold, 2002), indicating measurement invariance at the metric level and that the items were interpreted similarly across the cultural clusters. The results for the three variable groups show that scalar invariance is not achieved, indicating that the means of the variables vary across the cultural clusters. Achieving metric invariance is a sufficient result to pool the different cultural cluster samples in a single dataset, as the aim of the current study is to test the influence of cultural value dimensions on emotional intelligence and conflict handling styles in a pooled sample and not the comparison of variable means across the various cultural clusters.

The literature suggests that emotional intelligence is a hierarchical model and, thus, in addition to the first-order model we also conducted a CFA for the individual cultural cluster and a MGCFA for this variable. The results confirm the findings for the first-order factor model, indicating measurement invariance at the configural and the metric level but not at the scalar level. We also conducted CFA to evaluate the relative fit to the pooled sample data of a four factor model and a second-order four factor model for emotional intelligence. Overall, the results suggest that emotional intelligence should be specified as a second-order variable.

All variables included in our conceptual model were measured with the same surveys which might cause common method variance (e.g., Chang, Van Witteloostuijn, \& Eden, 2010; Reio, 2010). We applied two post hoc statistical control procedures to evaluate whether common method variance affects our results (Podsakoff, MacKenzie, Lee, \& Podsakoff, 2003). First, we conducted Harman's single-factor test and found no single factor that accounted for the majority of variance. Second, using the pooled sample we conducted two additional CFAs in which we added a

Table 2

Summary of multi-group confirmatory factor analysis.

\begin{tabular}{|c|c|c|c|c|c|c|c|c|}
\hline Model & $\chi^{2}$ & df & $p$ & $\chi^{2} / \mathrm{DF}$ & CFI & RMSEA & Models compared & $\Delta \mathrm{CFI}$ \\
\hline \multicolumn{9}{|l|}{ Cultural dimensions } \\
\hline Configural invariance & 955.73 & 658 & .000 & 1.45 & .939 & .018 & & \\
\hline Full metric invariance & 1062.89 & 724 & .000 & 1.47 & .931 & .018 & 2 vs. 1 & .007 \\
\hline Full scalar invariance & 1684.52 & 820 & .000 & 2.05 & .824 & .027 & 3 vs. 2 & .107 \\
\hline \multicolumn{9}{|c|}{ Emotional intelligence (first-order construct) } \\
\hline Configural invariance & 1097.28 & 686 & .000 & 1.60 & .965 & .020 & & \\
\hline Full metric invariance & 1192.05 & 758 & .000 & 1.57 & .963 & .020 & 2 vs. 1 & .002 \\
\hline Full scalar invariance & 1623.42 & 854 & .000 & 1.90 & .934 & .025 & 3 vs. 2 & .031 \\
\hline \multicolumn{9}{|c|}{ Emotional intelligence (second-order construct) } \\
\hline Configural invariance & 1134.60 & 700 & .000 & 1.62 & .965 & .021 & & \\
\hline Full metric invariance & 1232.63 & 772 & .000 & 1.60 & .961 & .020 & 2 vs. 1 & .004 \\
\hline Full scalar invariance & 1665.60 & 868 & .000 & 1.92 & .932 & .025 & 3 vs. 2 & .029 \\
\hline \multicolumn{9}{|l|}{ Conflict handling styles } \\
\hline Configural invariance & 1232.40 & 658 & .000 & 1.87 & .916 & .024 & & \\
\hline Full metric invariance & 1334.72 & 724 & .000 & 1.84 & .911 & .024 & 2 vs. 1 & .005 \\
\hline Full scalar invariance & 1857.81 & 820 & .000 & 2.27 & .848 & .029 & 3 vs. 2 & .063 \\
\hline
\end{tabular}

Note: $n=1527$. 
Table 3

Descriptive statistics of study variables.

\begin{tabular}{|c|c|c|c|c|c|c|c|c|c|c|c|c|c|c|c|c|c|c|c|}
\hline Variable & Mean & SD & 1 & 2 & 3 & 4 & 5 & 6 & 7 & 8 & 9 & 10 & 11 & 12 & 13 & 14 & 15 & 16 & 17 \\
\hline 1. Integrating & 4.15 & .63 & & & & & & & & & & & & & & & & & \\
\hline 2. Avoiding & 3.20 & .82 & .13 & & & & & & & & & & & & & & & & \\
\hline 3. Dominating & 2.83 & .88 & -.05 & .15 & & & & & & & & & & & & & & & \\
\hline 4. Obliging & 3.83 & .61 & .54 & .29 & .08 & & & & & & & & & & & & & & \\
\hline 5. Compromising & 3.75 & .62 & .55 & .23 & .12 & .49 & & & & & & & & & & & & & \\
\hline 6. Self emotional appraisal & 4.19 & .66 & .28 & .03 & .01 & .16 & .20 & & & & & & & & & & & & \\
\hline 7. Others emotional appraisal & 4.05 & .68 & .30 & .10 & .06 & .23 & .23 & .61 & & & & & & & & & & & \\
\hline 8. Regulation of emotion & 4.01 & .74 & .18 & .06 & -.01 & .16 & .17 & .63 & .46 & & & & & & & & & & \\
\hline 9. Use of emotion & 4.25 & .67 & .31 & .03 & .01 & .16 & .20 & .70 & .55 & .57 & & & & & & & & & \\
\hline 10. Emotional intelligence & 4.13 & .57 & .32 & .07 & .02 & .21 & .23 & .88 & .79 & .81 & .84 & & & & & & & & \\
\hline 11. Collectivism & 3.65 & .69 & .13 & .10 & -.07 & .13 & .06 & .04 & .07 & .10 & .05 & .08 & & & & & & & \\
\hline 12. Uncertainty avoidance & 4.05 & .54 & .25 & .07 & -.01 & .22 & .21 & .21 & .21 & .21 & .24 & .27 & .33 & & & & & & \\
\hline 13. Long term orientation & 4.25 & .62 & .26 & .06 & .03 & .20 & .22 & .24 & .19 & .22 & .33 & .30 & .22 & .37 & & & & & \\
\hline 14. Power distance & 2.14 & .75 & -.12 & .20 & .17 & .02 & -.09 & -.10 & -.08 & -.03 & -.10 & -.09 & .06 & -.09 & -.08 & & & & \\
\hline 15. Masculinity & 2.46 & .90 & -.12 & .17 & .12 & .03 & -.11 & -.08 & -.11 & -.01 & -.11 & -.09 & .10 & -.02 & -.04 & .51 & & & \\
\hline 16. English language skills & 9.39 & .73 & .06 & -.05 & .08 & .09 & .15 & .19 & .17 & .18 & .21 & .22 & -.09 & .03 & .09 & -.17 & -.16 & & \\
\hline 17. Age & 23.48 & 4.51 & .04 & -.10 & -.08 & -.14 & -.03 & .10 & .00 & .10 & .13 & .10 & .07 & .07 & .05 & -.01 & -.08 & -.02 & \\
\hline 18. Gender $($ female $=1)$ & .50 & .50 & .12 & .01 & -.10 & .04 & .09 & .03 & .14 & -.07 & .09 & .05 & -.12 & .04 & -.04 & -.18 & -.28 & -.02 & -.14 \\
\hline
\end{tabular}

Note: $n=1527$. All correlation equal to or above .05 and equal to or below -.05 are significant at $p<.05$.

common latent factor to the first-order measurement model and the second-order measurement model (Johnson, Rosen, \& Djurdjevic, 2011). The common latent factor loadings were insignificant for both models. In summary, the results suggest that common method variance was not a significant problem in the data set. Descriptive statistics and bivariate correlations of key study variables are presented in Table 3.

\subsection{Hypothesis testing}

To test our conceptual model and in particular mediating role of emotional intelligence in the relationship between cultural value dimensions and conflict handling styles, we followed the recommendations in the literature (e.g., Iacobucci, Saldanha, \& Deng, 2007; Zhao, Lynch, \& Chen, 2010) and used structural equation modeling (SEM), more specifically the SEM procedure suggested by James, Mulaik, and Brett (2006) as well as the bootstrapping procedure suggested by Cheung and Lau (2008). We used covariance-based structural equation modeling as it is of confirmatory nature, allows for higher order variables and enables us to test the mediation paths for the different dependent variables simultaneously and compare the hypothesized model with alternative models (partial mediation vs. full mediation vs. non-mediation).

First, we compared the partial mediation model with a full mediation model (James et al., 2006). In the full mediation model we excluded the direct paths from each of the five cultural value dimensions to each of the five conflict handling styles. The partial mediation model $\left(\chi^{2}=2463.67 ; \mathrm{df}=1021 ; p<.000 ; \quad \mathrm{CFI}=.95\right.$; RMSEA $=.03)$ had a significantly better fit $\left(\Delta \chi^{2}=296.39 ; \Delta d f=25\right.$; $p=.000)$ compared to the full mediation model $\left(\chi^{2}=2760.06\right.$; $\mathrm{df}=1046 ; p<.000 ; \mathrm{CFI}=.93$; RMSEA $=.03)$, indicating that cultural value dimensions also directly impact the conflict handling styles and not solely function through emotional intelligence. Next, we compared the partial mediation model with a nonmediation model, which included direct paths from the cultural value dimensions to the conflict handling styles but no paths from emotional intelligence to the conflict handling styles. The partial mediation model had a significantly better fit $\left(\Delta \chi^{2}=60.72\right.$; $\Delta \mathrm{df}=5 ; p<.000)$ compared to the non-mediation model $\left(\chi^{2}=2524.39 ; \mathrm{df}=1026 ; p<.000 ; \mathrm{CFI}=.94 ;\right.$ RMSEA $\left.=.03\right)$, indicating that the cultural value dimensions also indirectly impact the conflict handling styles through emotional intelligence. Comparison of the full mediation model and the non-mediation model shows that the full mediation model has a significantly better fit compared to the non-mediation model $\left(\Delta \chi^{2}=235.67 ; \Delta \mathrm{df}=20\right.$; $p<.000$ ). The SEM results for the best fitting model (the partial mediation model) are presented in Fig. 3.

Hypothesis 1 predicts that collectivism is positively related to (I) an integrating, (II) avoiding, (III) obliging, and (IV) a compromising conflict handling style and negatively related to (V) a dominating conflict handling style. The SEM results show that collectivism was positively and significantly associated with an integrating style $(.08 ; p<.05)$ as well as negatively and significantly related to a dominating style $(-.17 ; p<.01)$. Collectivism had no significant relationship with the three remaining conflict handling styles. These findings provide support for Hypotheses 1-I and 1-V. Hypotheses 1-II-1-IV are not supported.

Hypothesis 2 predicts that uncertainty avoidance is positively related to the conflict handing style of (I) integrating, (II) avoiding, (III) obliging, and (IV) compromising as well as that uncertainty avoidance is negatively related to $(\mathrm{V})$ a dominating conflict handling style. The results show that uncertainty avoidance was positively and significantly associated with an integrating style $(.14 ; p<.01)$, an avoiding style $(.09 ; p<.05)$, an obliging style $(.22$; $p<.001)$, as well as a compromising style $(.14 ; p<.01)$, providing support for Hypotheses 2-I-2-IV. Uncertainty avoidance was not significantly associated with a dominating style (.04). Therefore, Hypothesis 2-V is not supported.

Hypothesis 3 states that long-term orientation is positively related to the conflict handling styles of (I) integrating, (II) avoiding, (III) obliging, and (IV) compromising as well as that longterm orientation is negatively related to $(\mathrm{V})$ a dominating conflict handling style. The results show that long-term orientation was positively related with an integrating $(.15 ; p<.001)$, an obliging $(.09 ; p<.05)$, as well as on a compromising style $(.21 ; p<.001)$, providing support for Hypotheses 3-I, 3-III, and 3-IV. Long-term orientation had no significant relation with an avoiding style (.05). Therefore Hypothesis 3-III is not supported. Contrary to our Hypothesis 3-V, long-term orientation was positively and significantly associated with a dominating style $(.09 ; p<.05)$.

Hypothesis 4 predicts that power distance is positively related to the conflict handling styles of (I) avoiding and (II) dominating and negatively related to the conflict handling styles of (III) integrating, (IV) obliging, and (V) compromising. The results show that power distance was positively and significantly related with an avoiding style $(.24 ; p<.001)$ as well as with a dominating style $(.36$; $p<.001)$. Therefore, Hypotheses 4 -I and 4-II are supported. Power distance was not significantly associated with an integrating $(-.07)$, an obliging (.04), and a compromising (.05) conflict handling style. Thus, Hypotheses 4-III, 4-IV, and 4-V are not supported. 


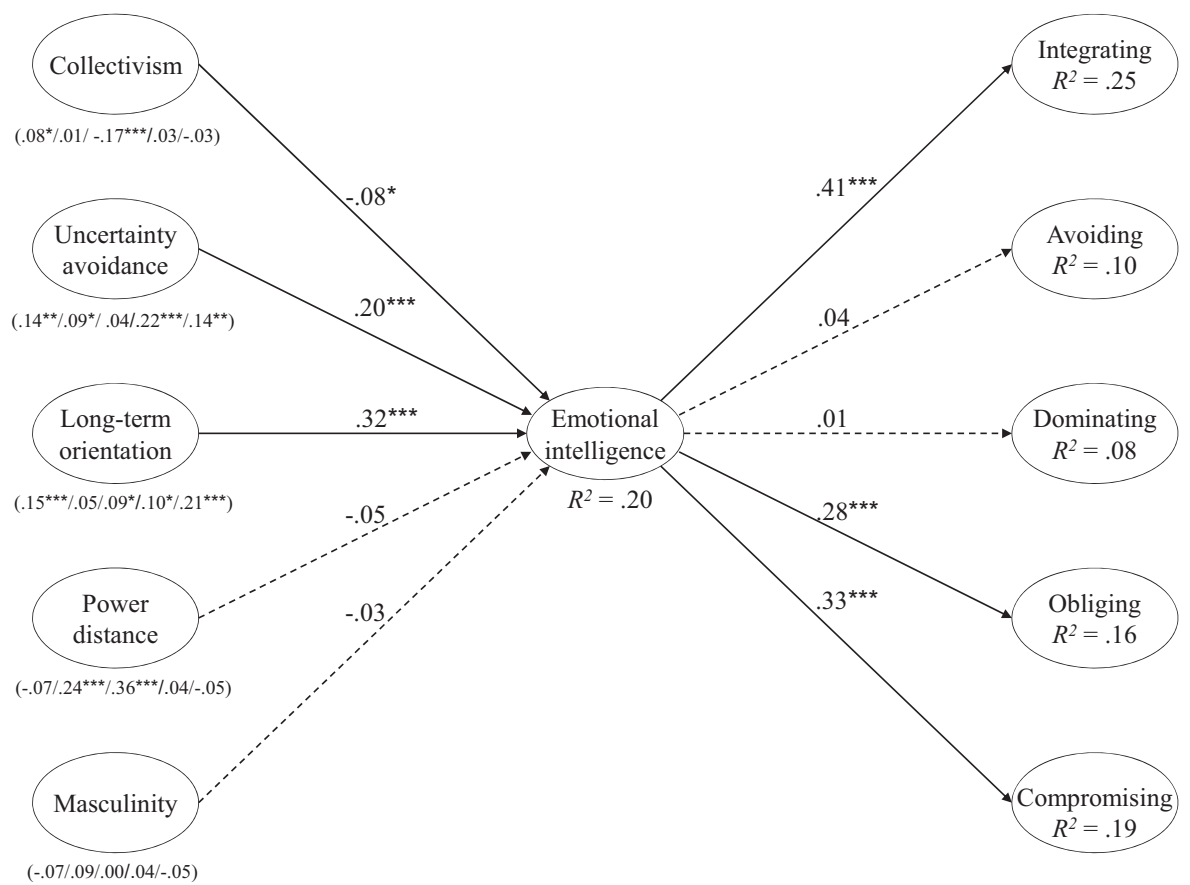

Fig. 3. Results of structural equation modeling.

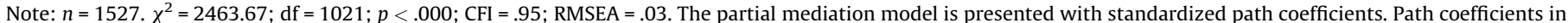

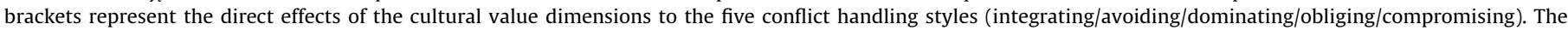

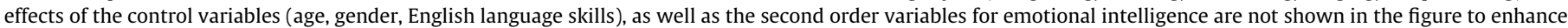

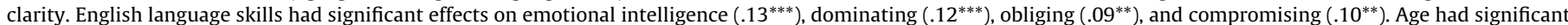

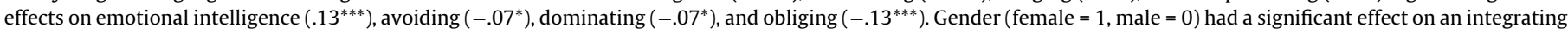
style $\left(.07^{*}\right){ }^{*} p<.05$; $^{* *} p<.01$; $^{* * *} p<.001$.

Hypothesis 5 predicts that masculinity is negatively related to the conflict handling styles of (I) integrating, (II) avoiding, (III) obliging, and (IV) compromising and is positively related to (V) a dominating conflict handling style. All five hypotheses are not supported as all relationships are not statistically significant $(-.07$, $09, .00, .04$, and -.05 respectively).

Several of the control variables had significant effects on different variables. English language skills had significant effects on emotional intelligence $(.13 ; p<.001)$ as well as a dominating $(.12 ; p<.001)$, obliging $(.09 ; p<.01)$, and compromising $(.10$; $p<.01)$ conflict handling style. Age had significant effects on emotional intelligence $(.13 ; p<.001)$ as well as an avoiding $(-.07$; $p<.05)$, dominating $(-.07 ; p<.05)$, and obliging $(-.13 ; p<.001)$ conflict handling style. Gender had a significant effect on an integrating conflict handling style $(-.07 ; p<.05)$. The control variables together explained a maximum of one percent of the variance in emotional intelligence and the conflict handling styles. While the coefficients are statistically significant they should be interpreted in light of the large sample size, the small effect sizes, and their practical meaningfulness. Meta-analytic studies have shown that the effects of cultural value dimensions for various outcomes are stronger for studies that use professionals instead of students and that use older rather than younger respondents (Steel \& Taras, 2010). As age had the strongest influence and in light of the student sample that we employ in the present study, we divided the sample into a 'younger' sample and an 'older' sample (above and below the mean/median age). The analyzes of the model shows that the main findings remained stable with the exception of the relationship between emotional intelligence and a compromising style which was not significant for the sample of older respondents. All other results remained stable. In sum, we believe that the control variables only make marginal contributions to the model while the theoretical constructs make the major contributions. While the student sample enables us to follow the recommendations in the literature (e.g., Harzing et al., 2013) to use equivalent samples across countries and therewith to increase internal validity, the use of such a sample reduces the external validity of the results. Carefully weighting the relative strengths and weaknesses of different samples we decided to use a student sample to reduce the influence of potential other influences in a more heterogeneous samples that are hard to control for and in this way to strengthen the internal validity.

To test the mediating mechanism we used bootstrapping (5000 bootstrap samples, maximum-likelihood procedure, and bias-corrected confidence intervals) to determine the significance of the indirect effects and total effects. A summary of the bootstrapping results are presented in Table 4.

Hypothesis 6 states that emotional intelligence mediates the relationship between collectivism and the five conflict handling styles. The results show that collectivism had a negative and statistically significant effect on emotional intelligence $(-.08$; $p<.05)$. Emotional intelligence had a positive and statistically significant effect on the integrating $(.41 ; p<.001)$, obliging $(.28$; $p<.001)$, and compromising $(.33 ; p<.001)$ styles. Emotional intelligence had neither a statistically significant effect on the avoiding nor the dominating style. The results of the bootstrapping procedure show that the standardized indirect effects of collectivism via emotional intelligence on the integrating $(-.02 ; p<.05)$, obliging $(-.01 ; p<.05)$, and compromising $(-.02 ; p<.05)$ styles were significant and negative. Therefore, Hypotheses 6a, 6d, and 6e are supported, while Hypotheses $6 \mathrm{~b}$ and $6 \mathrm{c}$ are not supported. Hypothesis 7 predicts that emotional intelligence mediates the relationship between uncertainty avoidance and the five conflict handling styles. The results show that uncertainty avoidance had a significant and positive impact on emotional intelligence (.20; $p<.001)$. The bootstrapping results show that the indirect effect of uncertainty avoidance via emotional intelligence on the integrating $(.05 ; p<.05)$, obliging $(.03 ; p<.05)$, and compromising 
Table 4

Summary of mediation analysis.

\begin{tabular}{|c|c|c|c|c|c|}
\hline Relationship & Hypothesis & Direct effect & \multicolumn{2}{|c|}{ Indirect effect } & Total effect \\
\hline \multicolumn{6}{|l|}{ Integrating } \\
\hline Collectivism $\rightarrow$ Integrating & $\mathrm{H} 6 \mathrm{a}$ & $.09^{*}$ & $-.02^{*}$ & $(-.04$ to -.01$)$ & .07 \\
\hline Uncertainty avoidance $\rightarrow$ Integrating & $\mathrm{H} 7 \mathrm{a}$ & $.12^{*}$ & $.05^{* * *}$ & $(.02$ to .07$)$ & $.17^{* *}$ \\
\hline Long-term orientation $\rightarrow$ Integrating & H8a & $.18^{* *}$ & $.08^{* * *}$ & $(.06$ to .11$)$ & $.25^{* * *}$ \\
\hline Power distance $\rightarrow$ Integrating & & -.04 & -.01 & $(-.04$ to .01$)$ & -.06 \\
\hline Masculinity $\rightarrow$ Integrating & & -.07 & -.01 & $(-.03$ to .01$)$ & -.08 \\
\hline \multicolumn{6}{|l|}{ Avoiding } \\
\hline Collectivism $\rightarrow$ Avoiding & $\mathrm{H} 6 \mathrm{~b}$ & .04 & -.01 & $(-.01$ to .00$)$ & .04 \\
\hline Uncertainty avoidance $\rightarrow$ Avoiding & $\mathrm{H} 7 \mathrm{~b}$ & $.09 *$ & .01 & $(-.01$ to .02$)$ & .10 \\
\hline Long-term orientation $\rightarrow$ Avoiding & $\mathrm{H} 8 \mathrm{~b}$ & .04 & .01 & $(-.01$ to .03$)$ & .05 \\
\hline Power distance $\rightarrow$ Avoiding & & $.21^{* * *}$ & -.01 & $(-.01$ to .00$)$ & $.21^{* * *}$ \\
\hline Masculinity $\rightarrow$ Avoiding & & $.11^{\dagger}$ & -.01 & $(-.01$ to .00$)$ & $.10^{\dagger}$ \\
\hline \multicolumn{6}{|l|}{ Dominating } \\
\hline Collectivism $\rightarrow$ Dominating & $\mathrm{H} 6 \mathrm{c}$ & $-.18^{* * *}$ & -.01 & $(-.01$ to .00$)$ & $-.18^{* * *}$ \\
\hline Uncertainty avoidance $\rightarrow$ Dominating & $\mathrm{H} 7 \mathrm{c}$ & .04 & .00 & $(-.01$ to .01$)$ & .04 \\
\hline Long-term orientation $\rightarrow$ Dominating & $\mathrm{H} 8 \mathrm{c}$ & $.13^{*}$ & .00 & $(-.02$ to .02$)$ & $.13^{\dagger}$ \\
\hline Power distance $\rightarrow$ Dominating & & $24^{* * *}$ & -.01 & $(-.01$ to .00$)$ & $.24^{* * *}$ \\
\hline Masculinity $\rightarrow$ Dominating & & .03 & .00 & $(-.01$ to .00$)$ & .03 \\
\hline \multicolumn{6}{|l|}{ Obliging } \\
\hline Collectivism $\rightarrow$ Obliging & H6d & .02 & $-.01^{*}$ & $(-.03$ to -.01$)$ & .00 \\
\hline Uncertainty avoidance $\rightarrow$ Obliging & H7d & $.19^{* *}$ & $.03^{* * *}$ & $(.02$ to .06$)$ & $.22^{* * *}$ \\
\hline Long-term orientation $\rightarrow$ Obliging & H8d & $.14^{* *}$ & $.05^{* * *}$ & (.03 to .08$)$ & $.20^{* *}$ \\
\hline Power distance $\rightarrow$ Obliging & & .04 & -.01 & $(-.02$ to .01$)$ & .03 \\
\hline Masculinity $\rightarrow$ Obliging & & .06 & -.01 & $(-.02$ to .01$)$ & .06 \\
\hline \multicolumn{6}{|l|}{ Compromising } \\
\hline Collectivism $\rightarrow$ Compromising & H6e & -.05 & $-.02^{*}$ & $(-.03$ to -.01$)$ & -.07 \\
\hline Uncertainty avoidance $\rightarrow$ Compromising & H7e & $.16^{* *}$ & $.03^{* * *}$ & $(.02$ to .06$)$ & $.19^{* *}$ \\
\hline Long-term orientation $\rightarrow$ Compromising & H8e & $.19^{* * *}$ & $.06^{* * *}$ & (.03 to .08$)$ & $.24^{* * *}$ \\
\hline Power distance $\rightarrow$ Compromising & & -.03 & -.01 & $(-.03$ to .01$)$ & -.04 \\
\hline Masculinity $\rightarrow$ Compromising & & -.06 & -.01 & $(-.02$ to .01$)$ & -.07 \\
\hline
\end{tabular}

Note: Results of the bootstrap procedure are presented (5000 bootstrap samples). $90 \%$ bias-corrected confidence intervals are presented in parentheses.

$(.03 ; p<.05)$ styles were significant and positive. Therefore, Hypotheses 7a, 7d, and 7e are supported, while Hypotheses 7b and 7c are not supported. Hypothesis 8 predicts that emotional intelligence mediates the relationship between long-term orientation and the five conflict handling styles. The results show that long-term orientation had a significant and positive impact on emotional intelligence $(.32 ; p<.001)$. The results of the bootstrapping procedure show that the indirect effects of long-term orientation via emotional intelligence on the integrating (.08; $p<.05)$, obliging $(.05 ; p<.05)$, and compromising $(.06 ; p<.05)$ styles were significant and positive. Therefore, Hypotheses $8 \mathrm{a}, 8 \mathrm{~d}$, and $8 \mathrm{e}$ are supported, while Hypotheses $8 \mathrm{~b}$ and $8 \mathrm{c}$ are not supported. We found no significant effect of masculinity and power distance on emotional intelligence. Moreover, we found no significant indirect effects for the relationships between power distance as well as masculinity and the different conflict handling styles. Overall, the cultural dimensions explain $20 \%$ of the variance in emotional intelligence.

\section{Discussion}

Conflict handling styles are an important part of individual behavior in interpersonal conflicts as the respective style used by an individual may positively or negatively influence the economic outcomes that are related to interpersonal conflicts in the business context. Based on a cultural-psychology perspective on intelligence (Miller, 1997) and integrating the literature on cultural value dimensions and emotional intelligence as determinants of individual preferences for conflict handling styles, we examine the impact of individuals' orientation toward cultural value dimensions on their preferences for specific conflict handling styles, mediated by emotional intelligence. Using data from 1527 individuals from ten different cultural clusters our study demonstrates that emotional intelligence partially mediates the influence of cultural value dimensions on conflict handling style preferences. Next, we discuss the theoretical and managerial implications of the results, review the limitations, and provide suggestions for future research.

Our study makes several contributions to the current literature. First, it contributes to earlier literature on the direct influence of cultural value dimensions on individuals' preferences for conflict handling styles. Following the recommendation in the literature (Kirkman et al., 2006; Tsui et al., 2007), we examined all five cultural dimensions proposed by Hofstede (2001) in our study. Moreover, we measured all five cultural dimensions at the individual level, whereas most of the pervious studies have considered culture as a societal level construct. In this way the present study addresses a methodological limitation that is consistently discussed when culture is inferred from individuals' nationality (Brewer and Venaik, 2014; Hofstede, 2001). By doing so, we extend the literature on culture's influence on conflict handling styles, which has so far primarily focused on the individualism vs. collectivism dimensions. We are able to confirm seven hypotheses on culture's effect on preferred conflict handling styles. We find that collectivism is positively related to an integrating style and negatively related to a dominating style of conflict handling. Uncertainty avoidance is positively related to an integrating style. Our results show that long-term orientation is related to the conflict styles of integrating and compromising. We find a positive relationship between power distance and an avoiding style as well as between power distance and a dominating conflict handling style. Our results suggest that masculinity has no influence on the preferred conflict handling style. These findings provide a more comprehensive view and more complete understanding of the influence of culture on individuals' preferences for conflict handling styles, offering guidance in evaluating the 
importance of culture compared to other determinants of conflict handling style preferences such as personality and individual characteristics.

The results of our study show the largest effect size related to the relationship between collectivism and specific conflict styles, namely integrating $(r=.13)$ and obliging $(r=.13)$, are smaller than or comparable to average effect sizes (e.g., Antonioni, 1998; Park and Antonioni, 2007; Wood and Bell, 2008) obtained for different personality traits and an integrating style (extraversion $r=.20$; openness $r=.18$; agreeableness $r=.18$ ) and an obliging style (openness $r=.17$; agreeableness $r=.14$ ). While the individualism/ collectivism dimension has been researched extensively, our findings suggest that compared to the widely neglected dimensions of uncertainty avoidance and long-term orientation the predictive power is much smaller in terms of effect sizes. The effect sizes related to the relationship between uncertainty avoidance as well as long-term orientation and an integrating style $(r=.25 / r=.26)$, an obliging style $(r=.22 / r=.20)$, as well as a compromising style $(r=.21 / r=.22)$ are larger than those observed for the collectivism dimension and comparable to those for personality traits. In sum our findings suggest that cultural dimensions influence individuals' preference for specific conflict handling styles. Collectivism, uncertainty avoidance, and longterm orientation predict in particular more favorable conflict styles (integrating, obliging, and compromising), while power distance determines less favorable styles (avoiding and dominating). The effects are in general comparable to the effect of personality, providing support for the model by Taras et al. (2010) that posits that cultural norms and values influence individuals' preferences and behavior. Our findings, to a large extent, are consistent with the culture fit perspective we used to frame our theoretical basis. Individuals seem to prefer those conflict handling styles that are consistent with their cultural values. In related research fields the findings of previous studies support the culture fit perspective. More specifically, these studies found an influence of cultural dimensions on individuals' preferences for learning styles and communication styles (e.g., Holtbrügge and Mohr, 2010; Merkin et al., 2014). The present study therewith contributes a new theoretical lens to view and examine individuals' preferences for specific conflict handling styles.

As a second contribution, the present study casts a new light on the role of emotional intelligence in the relationship between cultural value dimensions and preferences for conflict handling styles. In support of a cultural-psychology approach to emotional intelligence (Miller, 1997), our results confirm the findings of previous studies (Gunkel et al., 2014) by showing that collectivism, uncertainty avoidance, and long-term orientation are valid predictors of emotional intelligence. However, they find mixed results for the relationship between collectivism and emotional intelligence when it comes to the different dimensions of emotional intelligence. In contrast to the hypothesized positive association between collectivism and emotional intelligence, we find a negative relationship between collectivism and emotional intelligence. We argued that emotional intelligence may be an important aspect within collectivistic cultures as they are characterized by high context style of communication (Hofstede, 2001), requiring reading between lines and interpretation of messages. We expected that this may require the ability to understand emotions and to regulate and to use them. A potential explanation for the negative influence of collectivism on emotional intelligence might be that strong group norms within more collectivistic societies are more important than the individual ability to recognize, regulate, and alter emotions. If strong norms and informal rules are available within a society, such as losing face, these norms might have a more important influence on individuals' preferences than the individual ability to understand emotions.
We also find positive relationships between emotional intelligence and the integrating, obliging, and compromising styles of conflict handling. These positive styles of conflict handling (Jordan and Troth, 2004) require understanding of own and others' emotions as well as regulating them in order to reach solutions. These styles of conflict handling are seen in the literature as being more favorable and more desirable (e.g., Cerni, Curtis, \& Colmar, 2012) as the objectives, needs and wishes of the other conflict party are considered, which potentially results in a better solution of the conflict. Emotionally intelligent individuals are able to understand and control their own emotions which is certainly important in situations where one needs to give up own goals in order to find a solution, such as in case of compromising and obliging styles of conflict handling. Especially when it comes to the strategy of integrating, where problem solving might be a key issue, understanding others' emotions may become a crucial aspect contributing to the success of the strategy. Compared to the findings of the existing meta-analytic evidence (e.g., Holt \& DeVore, 2005), which examined the impact of various factors, such as different personality traits, on conflict handling style, our results show that both cultural value dimensions as well as emotional intelligence are relatively strong predictors of conflict handling styles, providing a more comprehensive understanding of the antecedents of the preferred conflict handling styles.

Our findings shed new light on the mechanism through which cultural values influence individuals' conflict handling styles. We examine both the direct and indirect effects of cultural value dimensions on the preferred conflict handling strategies. As emotional intelligence has been shown to be an important factor contributing to the selection of conflict handling styles, we extend this literature by examining if the relationship also holds in a multicultural team, which has become a prevalent work setting in a large number of today's organizations. As Gunkel et al. (2014) have shown, cultural value dimensions can be considered to be antecedents of emotional intelligence but at the same time they have a direct effect on the preferred conflict handling styles. Therefore, we extend the literature by examining both of these effects in a single model. Conceptualizing the mediating role of emotional intelligence represents an important contribution of our study. The influence of the three hypothesized cultural value dimensions is partially mediated by emotional intelligence, suggesting that cultural values indirectly and directly influence individuals' preferences toward the handling of conflict situations. These findings extend the model proposed by Oyserman et al. (2002), who propose that psychological functions, such as emotional intelligence, are influenced by culture. We show how culture influences emotional intelligence in conflicts by using the model of Taras et al. (2010) proposing that psychological characteristics have a mediating effect on the behavior of individuals. In line with the model, our results support the mediating relationship but also show that culture may have direct effects on behavior as well. All in all, our results provide a better understanding of the mechanism of culture's influence on individuals' preferred conflict handlings styles.

\subsection{Managerial relevance}

The results of the paper are of interest to the management of internationally active organizations as conflicts influence the effectiveness of an organization. Culture-sensitive handling of conflicts in organizations increases job satisfaction, positively affects work-related outcomes, and helps in training employees for international assignments. According to our results, emotional intelligence plays an important role in the selection of the preferred conflict handling style. That is, being able to assess the emotional intelligence of the employees helps the organizations to proceed 
toward more constructive conflict handling styles (Jordan \& Troth, 2004). For that purpose, organizations might consider assessing the emotional intelligence of their potential employees in the hiring process. As previous studies have demonstrated that workforce or classroom training can have a positive impact on emotional intelligence (e.g, Cherniss \& Caplan, 2001; Clarke, 2010), employees scoring lower in emotional intelligence may be trained in the aspects of emotional intelligence which may lead to more constructive conflict handling styles in the organization.

In our sample cultural value dimensions explained about $20 \%$ of the variance in emotional intelligence. That is, culture seems to be an important determinant of emotional intelligence. These culture based differences suggest that examining cultural dimensions at the individual level during the hiring process might provide a valuable insight when assessing emotional intelligence. In addition, the culture related differences in our results help to identify individuals requiring more intensive and specific emotional intelligence training. Our results also suggest a significant and positive relationship between language skills and emotional intelligence as well as the conflict handling styles of dominating, obliging, and compromising. These results demonstrate the importance of language skills in international project work. Therefore, internationally active organizations, which require international project work, should consider the language skills as an important determinant of emotional intelligence in an international work team. Testing for language skills of the working language of the organization may provide valuable information on the emotional intelligence of an employee in an international work group as well as their preferred conflict handling styles. Furthermore, such tests provide internationally active organizations information on the language training needs of their existing employees, resulting in an increase in emotional intelligence within an international work team and more constructive conflict handling styles.

\subsection{Limitations and future research directions}

Our findings and implications must be viewed in the light of the present study's limitations. First, while our sample includes participants from 83 countries and covers ten of the eleven cultural clusters identified by Ronen and Shenkar (2013), the sample size for the majority of countries was too small to conduct MGCFA across the different countries. Moreover, our sample does not cover the Near East cultural cluster, including Turkey and Greece. The results for the included cultural clusters show measurement invariance of the different constructs. However, future research should focus on a smaller number of countries that cover all cultural cluster as well as larger samples for the respective country samples to be able to test measurement invariance across countries in addition to measurement invariance across cultural clusters. Second, while the student sample enabled us to point out the specific effects of the cultural value dimensions, a student sample at the same time limits the generalizability of the results. The robustness test of the proposed conceptual model for two sub-samples (below the mean age and above the mean age) showed that except for one relationship, namely the link between emotional intelligence and a compromising style, the results are relatively stable. Meta-analytic findings show that age and education, among other factors, influence cultural values at the individual level (Merkin et al., 2014; Steel \& Taras, 2010) which in turn might influence the results for non-student samples. Therefore, future research should examine the direct and indirect effects of cultural values on employees' preferences for specific conflict handling styles. Third, given the large number of participants from different countries that are included in our sample we have not been able to adjust the questionnaire to the respective language of each participant. The question of instruction of the project was English and the results of the control variable that assessed the impact of English language skills on all variables were rather small for the statistically significant relationships. Furthermore, the results of the MGCFA suggest that the respondents understood the different constructs in a comparable way across the different cultural clusters. However, previous research shows that English language surveys may impact research findings (e.g., Harzing, 2005). Therefore, our findings should be interpreted in light of this methodological shortcoming and future research should focus on a smaller number of countries and use the respective national language for the questionnaire to avoid this limitation. Despite these limitations the results of the present study provide novel insights into the pathways through which cultural values influence conflict handling styles directly as well as indirectly through the mediating role of emotional intelligence.

Whereas our analysis is focused on the influence of emotional intelligence on conflict handling styles, many studies have focused on another intelligence, cultural intelligence, in order to examine culture specific differences in multicultural management practices. A number of studies (e.g., Crowne, 2009, 2013; Moon, 2010) have examined the relationship between emotional intelligence and cultural intelligence showing that the two concepts may be related but still distinct concepts. Therefore, emotional intelligence may be influenced by the cultural background of the individual and lead to different conflict handling styles. As these concepts are distinct, it becomes interesting to examine the influence of national culture on emotional intelligence, as one cannot assume that cultural intelligence would substitute emotional intelligence. As the concepts of emotional intelligence and cultural intelligence are somewhat related constructs, we believe that examining the influence of emotional intelligence in different cultures will also provide some insights to the possible influences of some facets of cultural intelligence. However, in order to understand the specific impacts of cultural intelligence on conflict handling styles, future studies should examine the construct of cultural intelligence in this particular context.

\section{Appendix A}

Appendix A provides a table with an overview of the quantitative empirical studies that have directly or indirectly examined the influence of cultural value dimensions on conflict handling styles. To the best of our knowledge 28 studies have tested the effect of cultural dimensions on conflict handling styles. 17 of these 28 studies have investigated the individualism/ collectivism dimension. Nine of these 17 studies have not directly measured individualism/collectivism and instead used the values provided by Hofstede, GLOBE or others to assign whether a country in the respective sample is more individualistic or more collectivistic. Only seven of the 17 studies directly measured this dimension in the survey. Three of these seven studies have been conducted in a single country, two studies have been conducted in two countries, one study has been conducted in four countries, and one study has been conducted with individuals from 31 countries (small sample size for each country). Two of the seven studies that have examined power distance directly measured this cultural dimension (in 4 and 5 countries respectively). Uncertainty avoidance has been examined in four studies (indirectly measured) and masculinity has been examined (indirectly measured) in two studies. Long-term orientation has not been examined directly and those studies that examined conflict styles and culture value dimensions have not reported effect sizes for these specific relationships.

The vast majority of previous research has not directly measured cultural value dimensions and has used secondary data instead of groups of different countries. The results based on such an analysis are problematic, e.g., the Hofstede scores that are often 
used in this literature stream have change for some of the dimensions (Taras et al., 2012). In light of this, one can argue that three of Hofstede's (2001) dimensions (uncertainty avoidance, masculinity, long-term orientation) have not been statistically tested in the existing literature. Moreover, those studies that directly measured and tested cultural value dimensions (individualism/collectivism and power distance) often utilized a singlecountry study design or often have examined two to five countries, which is considered to be insufficient to support generalizations across a broader set of countries (Franke \& Richey, 2010). While the existing research has provided important insights on the relationship between cultural value dimensions and conflict handling style preferences in different countries, the methodological shortcomings may compromise the fields' ability to determine whether and to which extent different cultural dimensions influence individuals preferences for conflict handling styles. By directly measuring the full set of cultural value dimensions across a large number of countries and cultural regions the present study overcomes these limitations.

Table A1

Table A1

Overview of empirical studies that directly or indirectly examined the influence of cultural value dimensions on conflict handling styles.

\begin{tabular}{|c|c|c|c|}
\hline Study & Cultural dimension & Conflict handling style & Operationalization of culture/countries \\
\hline Boros et al. (2010) & Individualism/collectivism & Avoidance, contending, cooperating & $\begin{array}{l}\text { Cultural dimension is directly measured } \\
\text { (horizontal/vertical individualism, } \\
\text { horizontal/vertical collectivism); } \\
\text { respondents from two countries (the } \\
\text { Netherlands and China) }\end{array}$ \\
\hline Brew \& Cairns (2004a) & Power distance & Avoid, diplomat, frank & $\begin{array}{l}\text { Cultural dimension is not directly } \\
\text { measured; respondents from two } \\
\text { groups (Western expatriates and Asian } \\
\text { host country nationals) }\end{array}$ \\
\hline Brew \& Cairns (2004b) & Individualism/collectivism & $\begin{array}{l}\text { Control, solution-oriented, non- } \\
\text { confrontational }\end{array}$ & $\begin{array}{l}\text { Cultural dimension is not directly } \\
\text { measured; respondents from two } \\
\text { groups (Anglos and Chinese) }\end{array}$ \\
\hline Cai \& Fink (2002) & Individualism/collectivism & $\begin{array}{l}\text { Avoiding, compromising, dominating, } \\
\text { integrating, obliging }\end{array}$ & $\begin{array}{l}\text { Cultural dimension is directly } \\
\text { measured, individuals from } \\
31 \text { countries }\end{array}$ \\
\hline $\begin{array}{l}\text { Corey, Fok, } \\
\text { \& Payne (2014) }\end{array}$ & Nine cultural value dimensions & $\begin{array}{l}\text { Accommodating, avoiding, competing, } \\
\text { collaborating, compromising }\end{array}$ & $\begin{array}{l}\text { Cultural dimensions are directly } \\
\text { measured; respondents from two } \\
\text { countries (Puerto Rico and the United } \\
\text { States) }\end{array}$ \\
\hline Croucher et al. (2012) & High vs. low context culture & $\begin{array}{l}\text { Avoiding, obliging, dominating, } \\
\text { compromising }\end{array}$ & $\begin{array}{l}\text { Cultural dimension is not directly } \\
\text { measured; respondents from four } \\
\text { countries (India, Ireland, Thailand, and } \\
\text { the United States) }\end{array}$ \\
\hline $\begin{array}{l}\text { Elsayed-EkJiouly } \\
\text { \& Buda (1996) }\end{array}$ & Individualism/collectivism & $\begin{array}{l}\text { Avoiding, compromising, dominating, } \\
\text { integrating, obliging }\end{array}$ & $\begin{array}{l}\text { Cultural dimension is not directly } \\
\text { measured; CHS means are compared for } \\
\text { one region and one country (Middle } \\
\text { East and the United States) }\end{array}$ \\
\hline Gabrielidis et al. (1997) & Individualism, masculinity & $\begin{array}{l}\text { Accommodating, avoiding, competing, } \\
\text { collaborating }\end{array}$ & $\begin{array}{l}\text { Cultural dimensions are not directly } \\
\text { measured; respondents from two } \\
\text { countries (Mexico and the United } \\
\text { States) }\end{array}$ \\
\hline He et al. (2002) & $\begin{array}{l}\text { Individualism,masculinity, } \\
\text { uncertainty avoidance, } \\
\text { power distance }\end{array}$ & $\begin{array}{l}\text { Dominating, integrating, } \\
\text { compromising, avoiding, obliging }\end{array}$ & $\begin{array}{l}\text { Cultural dimensions are not directly } \\
\text { measured; respondents from three } \\
\text { countries (US, France, China) }\end{array}$ \\
\hline Hong (2005) & Individualism/collectivism & $\begin{array}{l}\text { Accommodating, assertiveness, } \\
\text { avoiding, competition, collaboration, } \\
\text { compromise, cooperativeness }\end{array}$ & $\begin{array}{l}\text { Cultural dimension is not directly } \\
\text { measured; respondents from two } \\
\text { countries (Korea and the United States) }\end{array}$ \\
\hline Kaushal \& Kwantes (2006) & Individualism/collectivism & $\begin{array}{l}\text { Avoiding, contingency-based conflict } \\
\text { resolution strategy, dominating, } \\
\text { integrating, obliging }\end{array}$ & $\begin{array}{l}\text { Cultural dimension is directly measured } \\
\text { (horizontal/vertical individualism, } \\
\text { horizontal/vertical collectivism), } \\
\text { respondents from Canada }\end{array}$ \\
\hline $\begin{array}{l}\text { Kim-Jo, Benet-Martínez, } \\
\text { \& Ozer (2010) }\end{array}$ & Individualism/collectivism & Accommodating, avoiding, competing & $\begin{array}{l}\text { Cultural dimension is not directly } \\
\text { measured; respondents with three } \\
\text { different backgrounds (European- } \\
\text { American, Korean-American, Korean) }\end{array}$ \\
\hline Kim et al. (2007) & Power distance & $\begin{array}{l}\text { Integrating, obliging, avoiding, } \\
\text { compromising, dominanting }\end{array}$ & $\begin{array}{l}\text { Cultural dimension is directly } \\
\text { measured; respondents from three } \\
\text { countries (China, Japan, and Korea) }\end{array}$ \\
\hline Kim \& Meyers (2012) & Holism & $\begin{array}{l}\text { Accommodating, avoidance, competing, } \\
\text { collaborating, compromising }\end{array}$ & $\begin{array}{l}\text { Cultural dimension is directly } \\
\text { measured; respondents from two } \\
\text { countries (South Korea and the United } \\
\text { States) }\end{array}$ \\
\hline Komarraju et al. (2008) & Individualism/collectivism & $\begin{array}{l}\text { Avoiding, contingency-based conflict } \\
\text { resolution strategy, dominating, } \\
\text { integrating, obliging }\end{array}$ & $\begin{array}{l}\text { Cultural dimension is directly measured } \\
\text { (horizontal/vertical individualism, } \\
\text { horizontal/vertical collectivism), } \\
\text { respondents from the United States }\end{array}$ \\
\hline Kozan (1989) & Power distance & $\begin{array}{l}\text { Avoiding, forcing, accommodating, } \\
\text { compromise, collaboration }\end{array}$ & $\begin{array}{l}\text { Cultural dimensions are not directly } \\
\text { measured; respondents from three } \\
\text { countries (Jordan, Turkey, and the } \\
\text { United States) }\end{array}$ \\
\hline
\end{tabular}


Table A1 (Continued)

\begin{tabular}{|c|c|c|c|}
\hline Study & Cultural dimension & Conflict handling style & Operationalization of culture/countries \\
\hline Kozan \& Ergin (1999) & Nine cultural value dimensions by Schwartz & $\begin{array}{l}\text { Accommodating, avoiding, competing, } \\
\text { collaborating, compromising }\end{array}$ & $\begin{array}{l}\text { Cultural dimension are directly } \\
\text { measured; respondents from one } \\
\text { country (Turkey) }\end{array}$ \\
\hline Lee \& Rogan (1991) & Individualism/collectivism & $\begin{array}{l}\text { Nonconfrontation, solution-oriented, } \\
\text { control }\end{array}$ & $\begin{array}{l}\text { Cultural dimension is not directly } \\
\text { measured; respondents from two } \\
\text { countries (Korea and the United States) }\end{array}$ \\
\hline Ma, Erkus, \& Tabak (2010) & Individualism/collectivism & $\begin{array}{l}\text { Accommodating, avoiding, competing, } \\
\text { collaborating, compromising }\end{array}$ & $\begin{array}{l}\text { Cultural dimension is directly } \\
\text { measured, respondents from Turkey }\end{array}$ \\
\hline Morris et al. (1998) & $\begin{array}{l}\text { Individualism/collectivism, } \\
\text { social conservatism, self-enhancement, } \\
\text { openness to change }\end{array}$ & Avoiding, competing & $\begin{array}{l}\text { Cultural dimensions are directly } \\
\text { measured, respondents from four } \\
\text { countries (United States, China, } \\
\text { Philippines, and India) }\end{array}$ \\
\hline $\begin{array}{l}\text { Oetzel \& Ting-Toomey } \\
\text { (2003) }\end{array}$ & Individualism/collectivism & Avoiding, dominating, integrating & $\begin{array}{l}\text { Cultural dimension is not directly } \\
\text { measured; respondents from four } \\
\text { countries (China, Germany, Japan, and } \\
\text { the United States }\end{array}$ \\
\hline Oetzel et al. (2001) & Power distance & 13 categories & $\begin{array}{l}\text { Cultural dimension is directly } \\
\text { measured; respondents from four } \\
\text { countries (China, Germany, Japan, and } \\
\text { the United States) }\end{array}$ \\
\hline Oudenhoven et al. (1998) & $\begin{array}{l}\text { Power distance, uncertainty } \\
\text { avoidance, masculinity }\end{array}$ & $\begin{array}{l}\text { Problem solving, assertiveness, } \\
\text { emphasizing }\end{array}$ & $\begin{array}{l}\text { Cultural dimensions are not directly } \\
\text { measured; respondents from five } \\
\text { countries (Denmark, United Kingdom, } \\
\text { The Netherlands, Spain, Belgium) }\end{array}$ \\
\hline Purohit and Simmers (2006) & Power distance, uncertainty avoidance & $\begin{array}{l}\text { Accommodating, avoiding, } \\
\text { compromising, collaborating, } \\
\text { competing }\end{array}$ & $\begin{array}{l}\text { Cultural dimensions are not directly } \\
\text { measured; respondents from five } \\
\text { countries (US, Nigeria, and India) }\end{array}$ \\
\hline Posthuma et al. (2006) & Individualism/collectivism & $\begin{array}{l}\text { Accommodating, avoiding, contending, } \\
\text { compromise, collaborating, yield }\end{array}$ & $\begin{array}{l}\text { Cultural dimension is directly } \\
\text { measured, respondents from two } \\
\text { countries (Mexico and the United } \\
\text { States) }\end{array}$ \\
\hline Tang \& Kirkbride (1986) & Conformity, harmony ethics, and face & $\begin{array}{l}\text { Accommodating, avoiding, competing, } \\
\text { collaborating, compromising }\end{array}$ & $\begin{array}{l}\text { Cultural dimensions are not directly } \\
\text { measured; respondents from two } \\
\text { countries (Chinese managers in Hong } \\
\text { Kong and British expatriates) }\end{array}$ \\
\hline Ting-Toomey et al. (1991) & Individualism/collectivism & $\begin{array}{l}\text { Avoiding, compromising, dominating, } \\
\text { integrating, obliging }\end{array}$ & $\begin{array}{l}\text { Cultural dimension is not directly } \\
\text { measured; respondents from four } \\
\text { countries (Japan, China, South Korea, } \\
\text { Taiwan, and the United States) }\end{array}$ \\
\hline $\begin{array}{l}\text { Trubisky, Ting-Toomey, } \\
\text { \& Lin (1991) }\end{array}$ & Individualism/collectivism & $\begin{array}{l}\text { Avoiding, compromising, dominating, } \\
\text { integrating, obliging }\end{array}$ & $\begin{array}{l}\text { Cultural dimension is not directly } \\
\text { measured; respondents from two } \\
\text { countries (Taiwan and the United } \\
\text { States) }\end{array}$ \\
\hline
\end{tabular}

\section{References}

Antonioni, D. (1998). Relationship between the big five personality factors and conflic management styles. International Journal of Conflict Management, 9(4): 336-355.

Barbuto, J. E., Jr, Phipps, K. A., \& Xu, Y. (2010). Testing relationships between personality, conflict styles and effectiveness. International Journal of Conflict Management, 21(4): 434-447.

Bello, D., Leung, K., Radebaugh, L., Tung, R. L., \& Van Witteloostuijn, A. (2009). From the editors: student samples in international business research. Journal of International Business Studies, 40(3): 361-364.

Bergmann, T. J., \& Volkema, R. J. (1989). Understanding and managing interpersonal conflict at work: its issues, interactive processes, and consequences. In M. A. Rahim (Ed.), Managing conflict: an interdisciplinary approach (pp. 7-19). New York: Praeger.

Blake, R., \& Mouton, J. (1964). The managerial grid. Houston, TX: Gulf.

Bono, J. E., \& Barron, L. G. (2008). Leaders as emotional manager, across cultures. In N. M. Ashkanasy \& C. L. Cooper (Eds.), Research companion to emotion in organizations (pp. 489-511). Cheltenham: Edward Elgar.

Boros, S., Meslec, N., Curseu, P. L., \& Emons, W. (2010). Struggles for cooperation: conflict resolution strategies in multicultural groups. Journal of Managerial Psychology, 25(5): 539-554.

Bowles, S. (1998). Endogenous preferences: the cultural consequences of markets and other economic institutions. Journal of Economic Literature, 36(1): 75-111.

Bradford, K. D., Stringfellow, A., \& Weitz, B. A. (2004). Managing conflict to improve the effectiveness of retail networks. Journal of Retailing, 80(3): 181-195.

Brew, F. P., \& Cairns, D. R. (2004a). Do culture or situational constraints determine choice of direct or indirect styles in intercultural workplace conflicts? International Journal of Intercultural Relations, 28(5): 331-352.

Brew, F. P., \& Cairns, R. (2004b). Styles of managing interpersonal workplace conflict in relation to status and face concern: A study with Anglos and Chinese. International Journal of Conflict Management, 15(1): 27-56.

Brewer, P., \& Venaik, S. (2014). The ecological fallacy in national culture research. Organization Studies, 35(7): 1063-1086.

Brewer, N., Mitchell, P., \& Weber, N. (2002). Gender role, organizational status, and conflict management styles. International Journal of Conflict Management, 13(1): 78-94.

Browne, M. W., \& Cudeck, R. (1992). Alternative ways of assessing model fit Sociological Methods E' Research, 21(2): 230-258.

Bruk-Lee, V., \& Spector, P. E. (2006). The social stressors-counterproductive work behaviors link: are conflicts with supervisors and coworkers the same? Journal of Occupational Health Psychology, 11(2): 145-156.

Byrne, B. (2008). Testing for multigroup equivalence of a measuring instrument: a walk through the process. Psicothema, 20(4): 872-882.

Byrne, B. M., \& van De Vijver, F. J. (2010). Testing for measurement and structural equivalence in large-scale cross-cultural studies: addressing the issue of nonequivalence. International Journal of Testing, 10(2): 107-132.

Cai, D., \& Fink, E. (2002). Conflict style differences between individualists and collectivists. Communication Monographs, 69(1): 67-87.

Cerni, T., Curtis, G. J., \& Colmar, S. H. (2012). Cognitive-experiential self theory and conflict-handling styles: rational and constructive experiential systems are related to the integrating and compromising conflict-handling styles. International Journal of Conflict Management, 23(4): 362-381.

Chang, S.-J., Witteloostuijn, A., \& Eden, L. (2010). Common method variance in international business research. Journal of International Business Studies, 41(2): 178-184.

Chen, Y., Tjosvold, D., \& Fang, S. S. (2005). Working with foreign managers: conflict management for effective leader relationships in China. International Journal of Conflict Management, 16(3): 265-286.

Cherniss, C., \& Caplan, R. D. (2001). Implementing emotional intelligence programs in organizations. In C. Cherniss \& D. Goleman (Eds.), The emotionally intelligent workplace (pp. 286-304). San Francisco, CA: Jossey-Bass.

Cheung, G. W., \& Lau, R. S. (2008). Testing mediation and suppression effects of latent variables: bootstrapping with structural equation models. Organizational Research Methods, 11(2): 296-325.

Cheung, G. W., \& Rensvold, R. B. (2002). Evaluating goodness-of-fit indexes for testing measurement invariance. Structural Equation Modeling, 9(2): 233-255. 
Clarke, N. (2010). The impact of a training programme designed to target the emotional intelligence abilities of project managers. International Journal of Project Management, 28(5): 461-468.

Corey, C. M., Fok, L. Y., \& Payne, D. M. (2014). Cross-cultural differences in values and conflict management: a comparison of US and Puerto Rico. Journal of Organizational Culture, Communication and Conflict, 18(2): 59-78.

Croucher, S. M., Bruno, A., McGrath, P., Adams, C., McGahan, C., Suits, A., et al. (2012). Conflict styles and high-low context cultures: a cross-cultural extension. Communication Research Reports, 29(1): 64-73.

Crowne, C. A. (2009). The relationships among social intelligence: emotional intelligence and cultural intelligence. Organization Management Journal, 6: 148-163.

Crowne, C. A. (2013). An empirical analysis of three intelligences. Canadian Journal of Behavioral Science, 45(2): 105-114.

Derr, C. B. (1977). Managing organizational conflict. California Management Review, 21(2): 76-83.

Deutsch, M. (1990). Sixty years of conflict. International Journal of Conflict Management, 1(3): 237-263.

Doucet, L., Jehn, K. A., Weldon, E., Chen, X., \& Wang, Z. (2009). Cross-cultural differences in conflict management: an inductive study of Chinese and American managers. International Journal of Conflict Management, 20(4): 355-376.

Earley, P. C., \& Ang, S. (2003). Cultural intelligence: Individual interactions across cultures. Stanford University Press.

Elfenbein, H. A., \& Ambady, N. (2003). When familiarity breeds accuracy: cultural exposure und facial emotion recognition. Journal of Personality and Social Psychology, 85(2): 276-290.

Elsayed-EkJiouly, S. M., \& Buda, R. (1996). Organizational conflict: a comparative analysis of conflict styles across cultures. International Journal of Conflict Management, 7(1): 71-81.

Fang, T. (2003). A critique of Hofstede's fifth national dimension. International Journal of Cross Cultural Management, 3(3): 347-368.

Franke, G. R., \& Richey, R. G. (2010). Improving generalizations from multi-country comparisons in international business research. Journal of International Business Studies, 41(8): 1275-1293.

Friedman, R., Chi, S. C., \& Liu, L. A. (2006). An expectancy model of ChineseAmerican differences in conflict-avoiding. Journal of International Business Studies, 37(1): 76-91.

Gabrielidis, C., Stephan, W. G., Ybarra, O., Pearson, V. M. D. S., \& Villareal, L. (1997). Preferred styles of conflict resolution Mexico and the United States. Journal of Cross-Cultural Psychology, 28(6): 661-677.

Gbadamosi, O., Baghestan, A. G., \& Al-Mabrouk, K. (2014). Gender, age and nationality: assessing their impact on conflict resolution styles. Journal of Management Development, 33(3): 245-257.

Goleman, D. (1998). Working with emotional intelligence. New York, NY: Bantam Books.

Gunkel, M., Schlägel, C., \& Engle, R. L. (2014). Cultureäs influence on emotional intelligence: an empirical study of nine countries. Journal of International Management, 20(2): 256-274.

Harzing, A. W. (2005). Does the use of English-language questionnaires in crossnational research obscure national differences? International Journal of Cross Cultural Management, 5(2): 213-224.

Harzing, A. W. (2006). Response styles in cross-national survey research: a 26-country study. International Journal of Cross Cultural Management, 6(2): $243-266$.

Harzing, A. W., Reiche, B. S., \& Pudelko, M. (2013). Challenges in international survey research: a review with illustrations and suggested solutions for best practice. European Journal of International Management, 7(1): 112-134.

He, Z., Zhu, J., \& Peng, S. (2002). Cultural values and conflict resolution in enterprises in diverse cultural settings in China. In G. M. Chen \& R. Ma (Eds.), Chinese conflict management and resolution (pp. 129-147). CT, USA: Ablex Westport.

Hofstede, G. (1980). Culture's consequences. Beverly Hills, CA: Sage.

Hofstede, G. (2001). Culture's consequences: comparing values, behaviors, institutions, and organizations across nations (2nd ed.). Thousand Oaks: Sage Publications.

Hofstede, G., Hofstede, G. J., \& Minkov, M. (2010). Cultures and organizations. New York City, NY: McGraw-Hill.

Holt, J. L., \& DeVore, C. J. (2005). Culture, gender, organizational role, and styles of conflict resolution: a meta-analysis. International Journal of Intercultural Relations, 29(2): 165-196.

Holtbrügge, D., \& Mohr, A. T. (2010). Cultural determinants of learning style preferences. Academy of Management Learning E' Education, 9(4): 622-637.

Hong, J. (2005). Conflict management in an age of globalization: a comparison of intracultural and intercultural conflict management strategies between Koreans and Americans. Global Media Journal, 4(6): 1-19.

House, R. J., Hanges, P. J., Javidan, M., Dorfman, P. W., \& Gupta, V. (Eds.). (2004). Culture, leadership, and organizations: the GLOBE study of 62 societies. Sage publications.

Hult, G. T. M., Ketchen, D. J., Griffith, D. A., Finnegan, C. A., Gonzalez-Padron, T., Harmancioglu, N., et al. (2008). Data equivalence in cross-cultural international business research: assessment and guidelines. Journal of International Business Studies, 39(6): 1027-1044

Iacobucci, D. (2010). Structural equations modeling: fit indices, sample size, and advanced topics. Journal of Consumer Psychology, 20(1): 90-98.

Iacobucci, D., Saldanha, N., \& Deng, X. (2007). A meditation on mediation: evidence that structural equations models perform better than regressions. Journal of Consumer Psychology, 17(2): 139-153.
Inglehart, R. F. (1997). Modernization and postmodernization: cultural, economic, and political change in 43 societies. Princeton, NJ: Princeton University Press.

James, L. R., Mulaik, S. A., \& Brett, J. M. (2006). A tale of two methods. Organizational Research Methods, 9(2): 233-244.

Jehn, K. A. (1997). A qualitative analysis of conflict types and dimensions in organizational groups. Administrative Science Ouarterly, 42(3): 530-557.

Johnson, R. E., Rosen, C. C., \& Djurdjevic, E. (2011). Assessing the impact of common method variance on higher order multidimensional constructs. Journal of Applied Psychology, 96(4): 744-761.

Jordan, P. J., \& Troth, A. C. (2004). Managing emotions during team problem solving: emotional intelligence and conflict resolution. Human Performance, 17(2): 195-218.

Kaushal, R., \& Kwantes, C. T. (2006). The role of culture and personality in choice of conflict management strategy. International Journal of Intercultural Relations, 30(5): 579-603.

Kim, J., \& Meyers, R. (2012). Cultural differences in conflict management styles in East and West Organizations. Journal of Intercultural Communication, 29.

Kim, T. Y., Wang, C., Kondo, M., \& Kim, T. H. (2007). Conflict management styles: the differences among the Chinese, Japanese, and Koreans. International Journal of Conflict Management, 18(1): 23-41.

Kim-Jo, T., Benet-Martínez, V., \& Ozer, D. J. (2010). Culture and interpersonal conflict resolution styles: role of acculturation. Journal of Cross-Cultural Psychology, 41(2): 264-269.

Kirkbride, P. S., Tang, S. F., \& Westwood, R. I. (1991). Chinese conflict preferences and negotiating behaviour: cultural and psychological influences. Organization Studies, 12(3): 365-386.

Kirkman, B. L., Lowe, K. B., \& Gibson, C. B. (2006). A quarter century of culture's consequences: a review of empirical research incorporating Hofstede's cultural values framework. Journal of International Business Studies, 37(3): 285-320.

Komarraju, M., Dollinger, S. J., \& Lovell, J. L. (2008). Individualism-collectivism in horizontal and vertical directions as predictors of conflict management styles. International Journal of Conflict Management, 19(1): 20-35.

Kozan, M. K. (1989). Cultural influences on styles of handling interpersonal conflicts: comparisons among Jordanian, Turkish, and US managers. Human Relations, 42(9): 787-799.

Kozan, K., \& Ergin, C. (1999). The influence of intra-cultural value differences on conflict management practices. International Journal of Conflict Management, 10(3). 249-267.

Lachman, R., Nedd, A., \& Hinings, B. (1994). Analyzing cross-national management and organizations: a theoretical framework. Management Science, 40(1): 40-55.

Laurent, A. (1983). The cultural diversity of western conceptions of management. International Studies of Management and Organization, 13(1): 75-96.

Lee, H. O., \& Rogan, R. G. (1991). A cross-cultural comparison of organizational conflict management behaviors. International Journal of Conflict Management, 2(3): 181-199.

Leung, K., Bhagat, R. S., Buchan, N. R., Erez, M., \& Gibson, C. B. (2005). Culture and international business: recent advances and their implications for future research. Journal of International Business Studies, 36(4): 357-378.

Lin, X., \& Germain, R. (1998). Sustaining satisfactory joint venture relationships: the role of conflict resolution strategy. Journal of International Business Studies, 29(1): 179-196.

Littrell, R. F. (2012). Cultural value dimension theories: Hofstede-a work in progress. AIB Insights, 12(4): 3-6.

Ma, Z., Erkus, A., \& Tabak, A. (2010). Explore the impact of collectivism on conflict management styles: a Turkish study. International Journal of Conflict Management, 21(2): 169-185.

Marsh, A. A., Elfenbein, H. A., \& Ambady, N. (2003). Nonverbal "accents": cultural differences in facial expressions of emotion. Psychological Science, 14(4): 373-376.

Matsumoto, D. (1989). Cultural influences on the perception of emotion. Journal of Cross-Cultural Psychology, 20(1): 92-105.

Matsumoto, D., Yoo, Seung Hee, Nakagawa, Sanae, \& Multinational Study of Cultural Display Rules et al. (2008). Culture, emotion regulation, and adjustment. Journal of Personality and Social Psychology, 94(6): 925-937.

Matsumoto, D., Nezlek, J. B., \& Koopmann, B. (2007). Evidence for universality in phenomenological emotion response system coherence. Emotion, 7(1): 57-67.

Mayer, J. D., \& Salovey, P. (1997). What is emotional intelligence? In P. Salovey \& D. Sluyter (Eds.), Emotional development and emotional intelligence: educational implications (pp. 3-34). New York: Basic Books.

McSweeney, B. (2013). Fashion founded on a flaw. The ecological monodeterministic fallacy of Hofstede GLOBE, and followers. International Marketing Review, 30(5): 483-504.

Merkin, R., Taras, V., \& Steel, P. (2014). State of the art themes in cross-cultural communication research: a systematic and meta-analytic review. International Journal of Intercultural Relations, 38: 1-23.

Miller, J. G. (1997). A cultural-psychology perspective on intelligence. In R. J. Sternberg \& E. L. Grigorenko (Eds.), Intelligence, heredity, and environment (pp. 269-302). New York: Cambridge University Press.

Moon, T. (2010). Emotional intelligence correlates of the four-factor model of cultural intelligence. Journal of Managerial Psychology, 25(8): 876-898.

Morris, M. W., Williams, K. Y., Leung, K., Larrick, R., Mendoza, M. T., Bhatnagar, D., et al. (1998). Conflict management style: accounting for cross-national differences. Journal of International Business Studies, 29(4): 729-747.

Mulki, J. P., Jaramillo, F., Goad, E. A., \& Pesquera, M. R. (2015). Regulation of emotions, interpersonal conflict, and job performance for salespeople. Journal of Business Research, 68(3): 623-630. 
Nair, N. (2008). Towards understanding the role of emotions in conflict: a review and future directions. International Journal of Conflict Management, 19(4): 359-381

Ndubisi, N. O. (2011). Conflict handling, trust and commitment in outsourcing relationship: A Chinese and Indian study. Industrial Marketing Management, 40(1): 109-117.

Newman, K. L., \& Nollen, S. D. (1996). Culture and congruence: the fit between management practices and national culture. Journal of International Business Studies, 27(4): 753-779.

Nimon, K., \& Reio, T. G. (2011). Measurement invariance: a foundational principle for quantitative theory building. Human Resource Development Review, 10(2): 198-214.

Oetzel, J. G., \& Ting-Toomey, S. (2003). Face concerns in interpersonal conflict a cross-cultural empirical test of the face negotiation theory. Communication research, 30(6): 599-624.

Oetzel, J., Ting-Toomey, S., Masumoto, T., Yokochi, Y., Pan, X., Takai, J., et al. (2001) Face and facework in conflict: a cross-cultural comparison of China, Germany, Japan, and the United States. Communication Monographs, 68(3): 235-258.

Oudenhoven, J. P., Mechelse, L., \& Dreu, C. K. (1998). Managerial conflict management in five European countries: the importance of power distance, uncertainty avoidance, and masculinity. Applied Psychology, 47(3): 439-455

Oyserman, D., Kemmelmeier, M., \& Coon, H. M. (2002). Cultural psychology, a new look: reply to Bond (2002), Fiske (2002), Kitayama (2002), and Miller (2002). Psychological Bulletin, 128(1): 110-117.

Palmer, B. R., Gignac, G., Ekermans, G., \& Stough, C. (2008). A comprehensive framework for emotional intelligence. In R. J. Emmerling, V. K. Shanwal, \& M. K. Mandal (Eds.), Emotional intelligence: theoretical and cultural perspectives (pp. 17-38). New York, NY: Nova Science Publishers

Park, H., \& Antonioni, D. (2007). Personality, reciprocity, and strength of conflict resolution strategy. Journal of Research in Personality, 41(1): 110-125.

Pekerti, A. A., \& Thomas, D. C. (2003). Communication in intercultural interaction: an empirical investigation of idiocentric and sociocentric communication styles. Journal of Cross-Cultural Psychology, 34(2): 139-154.

Podsakoff, P. M., MacKenzie, S. B., Lee, J. Y., \& Podsakoff, N. P. (2003). Common method biases in behavioral research: a critical review of the literature and recommended remedies. Journal of Applied Psychology, 88(5): 879-903.

Posthuma, R. A., White, G. O., III, Dworkin, J. B., Yánez, O., \& Swift, M. S. (2006). Conflict resolution styles between co-workers in US and Mexican cultures. International Journal of Conflict Management, 17(3): 242-260.

Purohit, Y. S., \& Simmers, C. A. (2006). Power distance and uncertainty avoidance: a cross-national examination of their impact on conflict management modes. Journal of International Business Research, 5(1): 1-19.

Rahim, M. A. (1983). A measure of styles of handling interpersonal conflict. Academy of Management Journal, 26(2): 368-376.

Rahim, M. A. (1986). Referent role and styles of handling interpersonal conflict. Journal of Social Psychology, 126(1): 79-86.

Reio, T. G. (2010). The threat of common method variance bias to theory building Human Resource Development Review, 9(4): 405-411.

Ronen, S., \& Shenkar, O. (2013). Mapping world cultures: cluster formation, sources and implications. Journal of International Business Studies, 44(9): 867-897.

Salovey, P., \& Mayer, J. D. (1990). Emotional intelligenc. Imagination. Cognition and Personality, 9(3): 185-211

Schieman, S., \& Reid, S. (2008). Job authority and interpersonal conflict in the workplace. Work and Occupations, 35(3): 296-326.

Schlaerth, A., Ensari, N., \& Christian, J. (2013). A meta-analytical review of the relationship between emotional intelligence and leaders' constructive conflict management. Group Processes and Intergroup Relations, 16(1): 126-136.

Schmitt, N., \& Kuljanin, G. (2008). Measurement invariance: review of practice and implications. Human Resource Management Review, 18(4): 210-222.

Schutte, N. S., Malouff, J. M., Simunek, M., McKenley, J., \& Hollander, S. (2002). Characteristic emotional intelligence and emotional well-being? Cognition and Emotion, 16(6): 769-785.

Schwartz, S. H. (1994). Beyond individualism/collectivism: new cultural dimensions of values. In U. Kim, H. C. Triandis, C. Kagitcibasi, S.-C. Choi, \& G. Yoon (Eds.), Individualism and collectivism: theory, method and applications (pp. 85-119). Thousand Oaks, CA: Sage.

Schwartz, S. H. (2006). A theory of cultural value orientations: explication and applications. Comparative Sociology, 5(2-3): 137-182.

Sharma, S., Deller, J., Biswal, R., \& Mandal, M. (2009). Emotional intelligence: factorial structure and construct validity across cultures. International Journal of Cross Cultural Management, 9(2): 217-236.
Shao, B., Doucet, L., \& Caruso, D. R. (2014). Universality versus cultural specificity of three emotion domains some evidence based on the cascading model of emotional intelligence. Journal of Cross-Cultural Psychology, 46(2): 229-251.

Shih, H. A., \& Susanto, E. (2010). Conflict management styles, emotional intelligence, and job performance in public organizations. International Journal of Conflict Management, 21(2): 147-168.

Song, M., Dyer, B., \& Thieme, R. J. (2006). Conflict management and innovation performance: an integrated contingency perspective. Journal of the Academy of Marketing Science, 34(3): 341-356.

Steel, P., \& Taras, V. (2010). Culture as a consequence: a multi-level multivariate meta-analysis of the effects of individual and country characteristics on workrelated cultural values. Journal of International Management, 16(3): 211-233.

Tang, S. F., \& Kirkbride, P. S. (1986). Developing conflict management skills in Hong Kong: an analysis of some cross-cultural implications. Management Learning, 17(3): 287-301.

Taras, V., Kirkman, B. L., \& Steel, P. (2010). Examining the impact of culture's consequences: a three-decade, multilevel, meta-analytic review of Hofstede's cultural value dimensions. Journal of Applied Psychology, 95(3): 405-439.

Taras, V., Steel, P., \& Kirkman, B. L. (2012). Improving national cultural indices using a longitudinal meta-analysis of Hofstede's dimensions. Journal of World Business, 47(3): 329-341.

Taras, V., Rowney, J., \& Steel, P. (2013). Work-related acculturation: change in individual work-related cultural values following immigration. The International Journal of Human Resource Management, 24(1): 130-151.

Thomas, K. W. (1976). Conflict and conflict management. In M. Dunnette (Ed.), Handbook of industrial and organizational psychology (pp. 889-935). Chicago: Rand-Mc Nally.

Thomas, K. W. (1992). Conflict and conflict management: reflections and update. Journal of Organizational Behavior, 13(3): 265-274.

Thomas, K. W., \& Kilmann, R. H. (1974). Thomas-Kilmann conflict mode instrument. Tuxedo, NY: Xicom Inc

Ting-Toomey, S., Gao, G., Trubisky, P., Yang, Z., Kim, H. S., Lin, S. L., et al. (1991) Culture, face maintenance, and styles of handling interpersonal conflict: a study in five cultures. International Journal of Conflict Management, 2(4): 275-296.

Triandis, H. C. (1995). Individualism and collectivism. Boulder, CO: Westview Press.

Triandis, H. C., \& Gelfand, M. J. (1998). Converging measurement of horizontal and vertical individualism and collectivism. Journal of Personality and Social Psychology, 74(1): 118-128

Trubisky, P., Ting-Toomey, S., \& Lin, S. L. (1991). The influence of individualismcollectivism and self-monitoring on conflict styles. International Journal of Intercultural Relations, 15(1): 65-84.

Tsui, A. S., Nifadkar, S. S., \& Ou, A. Y. (2007). Cross-national, cross-cultural organizational behavior research: advances, gaps, and recommendations. Journal of Management, 33(3): 426-478.

van De Vijver, F. J. R., \& Leung, K. (1997). Methods and data analysis for cross-cultural research. Newbury Park, CA: Sage.

Wall, J. A., \& Callister, R. R. (1995). Conflict and its management. Journal of Management, 21(3): 515-558.

Wang, C. L., Lin, X., Chan, A. K., \& Shi, Y. (2005). Conflict handling styles in international joint ventures: a cross-cultural and cross-national comparison. MIR: Management International Review, 45(1): 3-21.

Weldon, E., \& Jehn, K. A. (1995). Examining cross-cultural differences in conflict management behavior: a strategy for future research. International Journal of Conflict Management, 6(4): 387-403.

Wong, C.-S., \& Law, K. S. (2002). The effects of leader and follower emotional intelligence on performance and attitude: an exploratory study. The Leadership Quarterly, 13(3): 243-274.

Wood, V. F., \& Bell, P. A. (2008). Predicting interpersonal conflict resolution styles from personality characteristics. Personality and Individual Differences, 45(2): $126-131$.

Xie, J., Song, X. M., \& Stringfellow, A. (1998). Interfunctional conflict, conflict resolution styles, and new product success: a four-culture comparison. Management Science, 44(12, part 2): 192-206.

Yoo, B., Donthu, N., \& Lenartowicz, T. (2011). Measuring Hofstede's five dimensions of cultural values at the individual level: development and validation of CVSCALE. Journal of International Consumer Marketing, 23(3-4): 193-210.

Yu, C. S., Sardessai, R. M., Lu, J., \& Zhao, J. H. (2006). Relationship of emotional intelligence with conflict management styles: an empirical study in China. International Journal of Management and Enterprise Development, 3(1): 19-29.

Zhao, X., Lynch, J. G., \& Chen, Q. (2010). Reconsidering Baron and Kenny: myths and truths about mediation analysis. Journal of Consumer Research, 37(2): 197-206. 